\title{
Earnings Volatility in America: Evidence from Matched CPS
}

\author{
James P. Ziliak \\ Department of Economics \\ Center for Poverty Research \\ University of Kentucky \\ Bradley Hardy \\ Department of Public Administration \& Policy \\ American University \\ Christopher Bollinger \\ Department of Economics \\ University of Kentucky
}

Preferred citation

Ziliak, James P; Hardy, Bradley; Bollinger, Christopher. (September, 2011). Earnings Volatility in America: Evidence from Matched CPS. University of Kentucky Center for Poverty Research Discussion Paper Series, DP2011-03. Retrieved [Date] from http://www.ukcpr.org/Publications/DP2011-03.pdf.

Author correspondence

James P. Ziliak, Department of Economics, University of Kentucky, Lexington, KY 40506-0034. E-mail: jziliak@uky.edu. Phone: 859-257-2776.

University of Kentucky Center for Poverty Research, 302D Mathews Building, Lexington, KY, 40506-0047 Phone: 859-257-7641; Fax: 859-257-6959; E-mail: mary.boulton@uky.edu 


\title{
Earnings Volatility in America: Evidence from Matched CPS
}

\author{
James P. Ziliak \\ Department of Economics \\ and \\ Center for Poverty Research \\ University of Kentucky \\ Bradley Hardy \\ Department of Public Administration \& Policy \\ American University \\ Christopher Bollinger \\ Department of Economics \\ University of Kentucky
}

Revised June 2011

* Address correspondence to James P. Ziliak, Department of Economics, University of Kentucky, Lexington, KY 40506-0034; Email: jziliak@uky.edu; Phone: 859-257-2776. We thank Richard Burkhauser and Jeff Larrimore for generously providing their data on consistent top-codes in the CPS. We benefitted from the comments of the editor, two anonymous referees, Tom Deleire, and participants at the $3^{\text {rd }}$ World Congress of EALE/SOLE, the 2010 Institute for Research on Poverty Summer Workshop, and the APPAM Fall 2010 Conference. All errors are our own. 
Abstract: We offer new evidence on earnings volatility of men and women in the United States over the past four decades by using matched data from the March Current Population Survey. We construct a measure of total volatility that encompasses both permanent and transitory instability, and that admits employment transitions and losses from self employment. We also present a detailed decomposition of earnings volatility to account for changing shares in employment probabilities, conditional variances of continuous workers, and conditional mean variances from labor-force entry and exit. Our results show that earnings volatility among men increased by 15 percent from the early 1970s to mid 1980s, while women’s volatility fell, and each stabilized thereafter. However, this pooled series masks important heterogeneity in volatility levels and trends across education groups and marital status. We find that men's earnings volatility is increasingly accounted for by employment transitions, especially exits, while the share of women's volatility accounted for by continuous workers rose, each of which highlights the importance of allowing for periods of non-work in volatility studies. 
Whether and to what extent the volatility of earnings and income have increased in the United States in recent decades has been the subject of much research and debate (Gottschalk and Moffitt 1994, 2009; Dynarski and Gruber 1997; Haider 2001; Kniesner and Ziliak 2002a,b; Gundersen and Ziliak 2003; Dahl, DeLeire, and Schwabish 2008; Dynan, Elmendorf, and Sichel 2008; Hacker and Jacobs 2008; Jensen and Shore 2008; Keys 2008; Shin and Solon 2008; Winship 2009). Starting with Gottschalk and Moffitt (1994), the focus on volatility trends centered on identifying whether rising cross-sectional income inequality stemmed in part from transitory instability, while in more recent years interest in volatility expanded to concerns raised by Hacker and Jacobs (2008), among others, that there have been fundamental changes in the labor market that shifted more idiosyncratic and business cycle risk onto individuals. Whereas the preponderance of evidence on inequality in the United States is based on cross-section data from the Current Population Survey (CPS), with few exceptions the evidence on earnings and income volatility comes almost exclusively from longitudinal data in the Panel Study of Income Dynamics (Gittleman and Joyce 1996; Cameron and Tracy 1998; Dahl, et al. 2008; Celik, et al. 2009; Juhn and McCue 2010; Winship 2011). In this paper we offer new evidence on earnings volatility over the past four decades by exploiting the longitudinal dimension of the CPS to match individuals across surveys.

The use of the PSID for estimates of volatility owes in part to the literature's early emphasis on decomposing volatility into its permanent and transitory components (Gottschalk and Moffitt 1994). This decomposition is illustrative because it permits identification of temporary deviations of earnings from long-term trends, as well as identification of structural changes in long-term trends. A common result was that transitory earnings instability rose by over 40 percent from 1970 through the mid 1980s, and then more or less stabilized thereafter, 
while lifetime inequality rose primarily in the 1980s (Gottschalk and Moffitt 1994; Haider 2001). Although most of the papers were based on samples of prime-age men, Keys (2008) finds that the basic pattern of results hold across race, gender, education, and family structure in the PSID. More recently attention has turned to more basic measures of volatility. Because much of the literature reports the variance of log earnings, person-years with zero earnings are dropped, which can understate measured volatility because labor-force dropouts are ignored. Dynan, et al. (2008) proposed a more transparent measure of volatility —-the standard deviation of the arc percent change - which also admits person-years with zero earnings and/or incomes. Using the PSID they found that earnings volatility rose 40 percent. On the other hand, Dahl, et al. (2008) used the arc percent change along with administrative earnings records matched to longitudinal data in the SIPP and found little change in measured volatility after the mid 1980s, underscoring that the volatility literature is far from consensus.

We extend the research on the evolution of earnings volatility in several directions. First, we use data from matched CPS files spanning 1973-2009, which makes our results more directly informative to the CPS-based inequality research. ${ }^{1}$ The rotating structure of the CPS permits one

\footnotetext{
${ }^{1}$ We are aware of a few related studies using matched CPS. Gittleman and Joyce (1996) use matched CPS data to estimate earnings mobility and inequality from 1968-1992, focusing on shifts in permanent earnings differences rather than volatility. Cameron and Tracy (1998) use matched CPS data to examine earnings instability of working men, focusing on the permanent/transitory distinctions found in Gottschalk and Moffitt (1994). Celik, et al. (2009) and Winship (2011) employ matched CPS to compare to SIP and PSID volatility trends. Our study differs by our focus on men and women whether working or not, a wide array of demographic
} 
to match approximately 50 percent of sample respondents in one March survey to the March survey the subsequent year. Second, we extend the summary measure of volatility used in Dynan, et al. (2008) and Dahl, et al. (2008) so it is robust not only to those workers transitioning in and out of the labor market but also to negative earnings commonly found among the self employed. Most of the literature measures earnings volatility in terms of the growth in log earnings, which precludes those with zero or negative earnings. However, there has been trend growth in the fraction of the labor force that is self employed, as well as growth in the fraction of men out of the labor force and in the fraction of women in the labor force, and our measure captures this shifting composition. In this context we relate our measure to others used in the literature such as Gottschalk and Moffitt (1994) and Shin and Solon (2010), including the roles of lifecycle age adjustment, self employment, and non-employment.

Third, since 1970 there have been dramatic changes in the composition of the labor force, and this change in composition could have an important effect on earnings volatility. Most prior research has focused on continuous working men, and thus misses the influence of transitions and shifting composition of the labor force. To investigate this we decompose the unconditional variance of earnings volatility into the sum of the variance of the conditional mean and the conditional variance. Because each of the latter two terms are a function of whether an individual is transitioning into or out of employment, or always in or out of work, we can examine the changing contributions of employment probabilities, variance of conditional means, and conditional variances to earnings volatility. Fourth, because CPS samples are much larger

groups, and a variance decomposition distinguishing the role of labor-force transitions compared to continuous work in measured volatility. 
compared to the PSID, we are able to estimate earnings volatility trends with precision for detailed subgroups by race, and family structure.

Our results show that earnings volatility among men increased by 15 percent from the early 1970 s to mid 1980s, and stabilized thereafter. However, this pooled series masks important subgroup heterogeneity—increased volatility occurred among married men and earnings volatility rose faster among less skilled men compared to high skilled from 1973-1984 (24 versus 6 percent), and then reversed from 1986-2008 (1 versus 21 percent). Moreover, our results show that men's earnings volatility are increasingly accounted for by employment transitions, especially exits, as opposed to continuous workers, highlighting the importance of allowing for periods of non-work in volatility studies. For women, we find a secular decline in earnings volatility, especially among those with high school or more and those who are married, and indeed there is evidence of convergence in levels to those of men. Moreover, the share of women's earnings volatility from employment transitions fell in relation to the share from continuous work as women moved more permanently into employment. The overall trends of earnings volatility from matched CPS files tend to corroborate those in the PSID, and to a lesser extent, SIPP.

\section{Data}

The data derive from the 1973-2009 waves (1972-2008 calendar years) of the March Annual Social and Economic Study of the Current Population Survey (CPS). The unit of observation is an individual between the ages of 16 and 60 . This is intentionally a wider age range than many previous studies that focus on prime-age workers in order to provide a more comprehensive portrait of volatility across the population. The rotating design of the CPS means that a respondent is in sample for 4 months, out 8 months, and in another 4 months, and this 
makes it possible to match approximately one-half of the sample from one March interview to the next. Following the recommended Census procedure we perform an initial match of individuals on the basis of five variables — month in sample (months 1-4 for year 1, months 5-8 for year 2); gender; line number (unique person id); household identifier; and household number. We then cross check the initial match on three additional criteria: race, location, and age of the individual. If the race or state of residence of the person changed we delete that observation. Also, if the age of the person fell, or if age increased by more than two years (owing to the staggered timing of the initial and final interviews), then we delete those observations on the assumption that they were bad matches. These additional criteria were very important prior to the 1986 survey year, but thereafter the five base criteria matched most observations.

Prior to matching across years, we address two issues with the CPS data. First, if the respondent refuses to supply information on earnings or nonlabor income, then the Census Bureau uses a "hotdeck" imputation method to allocate income to those with missing data. Bollinger and Hirsch (2006) argue that including allocated data generally leads to an attenuation bias on estimated regression coefficients based on imputed data. Although the implications of hot decking for moments of the distribution beyond the mean are not well known, we follow Bollinger and Hirsch (2006) and drop those observations with allocated earnings or income. These observations are dropped prior to matching. Second, in a series of papers, Richard Burkhauser and co-authors (Burkhauser, et al. 2004; 2007; Larrimore, et al. 2008) have raised concerns about trends in income inequality because of changes in the way the Census top-codes income data for public release. Prior to 1995 the Census assigned top-coded data a common value (though this value varied across income sources, and at times, years), but starting in 1995 they assigned top-coded data the mean values of actual income based on broad demographic 
groupings (age, race, gender, education). Larrimore, et al. (2008) obtained access to internal Census data, which allowed them to back-cast the post-1995 procedure to 1976 and thus provide a consistent method of top-coding from 1976 onwards. We incorporated their series into our data prior to matching across years.

There were major survey redesigns in the mid 1980s and mid 1990s so it is not possible to match across the 1985-1986 waves and the 1995-1996 waves. In addition, the line number, which is intended to uniquely identify a person in the household, was not recorded for the 19761978 survey years, and in 1977 there were changes in the format of matching variables. This yields an interrupted time series across 36 years with gaps in calendar years 1974-1975, 19751976, 1984-1985, and 1994-1995. As indicated in Appendix Table 1, we have 640,412 matches, or roughly 20,000 observations in an average year when a match is possible. Appendix Table 1 also summarizes the number and rate of matches for each year, indicating that we match approximately 52 percent across survey years on average. The declining match rate after the mid 1990s reflects in part a rise in allocation within the CPS after adoption of CATI-CAPI interviewing. As the right columns indicate if we retain individuals with allocated earnings and income then we match just over 62 percent across years. ${ }^{2}$ A possible concern then with

${ }^{2}$ We note that this match rate of individuals is much lower than the average rate of 75 percent reported by Cameron and Tracy (1998). (In footnote 2 they claim to match 87 percent of households, and of these 87 percent of individuals in these households). We have not conducted a full replication but we note that they matched based on line number, age, race, and gender; whereas we matched on these criteria as well as household number, household identifier, and state of residence. Match rates can also differ based on the amount of pre-match data cleaning one undertakes. For example, Cameron and Tracy focus only on men who are not in school, who 
declining match rates is with sample attrition affecting our volatility series. Under the assumption that the probability of attrition is unobserved and time invariant (i.e., a fixed effect), then differencing the variable will remove the latent effect (Ziliak and Kniesner 1998; Wooldridge 2001). Our measure of volatility described in the next section involves first differencing earnings, and thus under the maintained assumption that attrition is person-specific and time invariant, we believe potential attrition bias will be attenuated. ${ }^{3}$

Our primary variable of interest is total labor-market earnings. Earnings is defined as the sum of wage and salary income, non-farm self employment, and farm self employment. As described in the results section we also examine volatility omitting self employment earnings. Unless noted otherwise all earnings data are deflated by the Personal Consumption Expenditure Deflator with 2008 base year. Basic summary statistics are provided in Appendix Table 2.

\section{Trends in Earnings Volatility}

We measure earnings volatility as the standard deviation of the arc percent change work in both periods, and whose earnings are within 1.5 and 98.5 percentiles. Our sample includes women, non-participants, the self employed, and students, and also excludes those with allocated nonlabor income. We also do not trim the top and bottom earners.

${ }^{3}$ As suggested by an anonymous reviewer, if there is a time-varying factor loading on the unobserved heterogeneity then differencing will not eliminate potential attrition bias. A conservative interpretation, then, is that data from matched CPS provides estimates of volatility among the population of non-movers. Even if this is true it is still not clear a priori whether potential time-varying attrition affects overall trends in volatility as moves can be accompanied by downward movements in earnings, upward movements in earnings, or no change at all. A full evaluation of the extent of attrition bias in the CPS is beyond the scope of the current paper. 


$$
\text { volatility }=\sqrt{\operatorname{Var}\left\{100 * \frac{y_{i t}-y_{i t-1}}{\bar{y}_{l}}\right\}},
$$

where $y_{i t}$ is earnings for person $i$ in time $t$, and $\overline{y_{l}}=\frac{y_{i t}+y_{i t-1}}{2}$, which is the person-specific time mean across the matched pair of years (Dynan, et al. 2008). The key advantage of this measure over the variance of log earnings used in most of the prior literature is that it is defined even if earnings are zero in one of the two years, and that it is symmetric and bounded below by -200 percent and above by +200 percent. However, the symmetry property is violated if earnings are negative one year, say due to a business loss, and positive the next. As a consequence we modify the arithmetic mean in the denominator as $\bar{y}_{l}=\frac{a b s\left(y_{i t}\right)+a b s\left(y_{i t-1}\right)}{2}$, where $a b s($.$) refers to the$ absolute value. This modified measure at once permits negative earnings and retains the symmetry property of -200 percent and +200 percent. ${ }^{4}$ In addition, as shown below there is a rising share of the male population out of employment two years in a row, and after declining through the mid 1990s it has been rising among women as well. By definition earnings volatility of these individuals is zero, but because we are interested in a population measure of volatility we want to retain these individuals and thus set earnings volatility to zero in our baseline series. Below we explore the sensitivity of our results to inclusion of the self employed and zeroearners.

[Figure 1 here]

\footnotetext{
${ }^{4}$ We note that it is possible for a worker to have nonzero earnings that are equal but opposite in sign across years, and instead of averaging to zero our measure reports the average as the absolute value of one of the years. In practice we find that this is not an issue and we do not lose any observations due to equal and opposite in sign earnings.
} 
Figure 1 depicts trends in year-to-year individual earnings volatility for men (top panel) and women (bottom panel). ${ }^{5}$ The top panel of the figure shows that in our baseline series earnings volatility of men increased sharply through the 1970s and into the mid 1980s, rising 15 percent, which roughly corroborates findings from the PSID. The 1986 redesign of the CPS reset the sample to coincide with the 1980 Decennial Census, which initially resulted in a sharp decrease in the level of volatility but not the trend. By the 1996 redesign, which reset the CPS sample to coincide with the 1990 Census, the overall increase in earnings volatility over the 36year period had been realized. The top panel also depicts trend volatility when we retain those men for whom earnings were allocated (denoted with circles). There is no substantive difference in trends in this case, though the levels of volatility in any given year are about 10-15 percent higher. Whereas allocated earnings tend to attenuate regression coefficients (Bollinger and Hirsch 2006), variances appear to be exacerbated. It is common in the literature to adjust earnings (Gottschalk and Moffitt 1994) or the change in earnings (Shin and Solon 2010) for lifecycle age effects. In the series denoted with squares we report trend volatility based on residuals from a regression of the standard deviation of the arc percent change on a quadratic in age. As is apparent, this has little effect on trends or levels. ${ }^{6}$

In the bottom panel of Figure 1 we see that among women there was a substantial secular decline in earnings volatility of about 20 percent from the late 1970s through the 1980s, where it held relatively steady in the 1990s, and then fell slightly further through 2008. Indeed, if the

\footnotetext{
${ }^{5}$ Dynan et al. (2008) report 3-year moving averages rather than annual changes owing to smaller samples in the PSID. The large samples in the CPS make smoothing less important, but for completeness we conducted our entire analysis with 3-year averages with little change in results.

${ }^{6}$ We also estimated the series with a quartic in age with no change in the results.
} 
volatility trends of men and women continue the levels are likely to converge in the current decade, and in fact this convergence has already taken place between unmarried men and women (see Figure 8 below). Similar to men in the top panel, including allocated earnings or adjusting for lifecycle age effects has no impact on trend volatility among women, though again the levels of volatility are higher with allocated earnings, but less so than with men. This, too, is consistent with Bollinger and Hirsch (2010) who find the effects of earnings nonresponse to be less important among women than men.

[Table 1 here]

In addition to secular trends, another important feature of the literature on volatility is its relationship to the business cycle, where it is generally found to be counter-cyclical, i.e. volatility increases during recessions and declines during expansions. The top panel of Figure 1 regarding men in matched CPS samples appears to support the counter-cyclical tendency, but it is much more difficult to discern the business cycle effects in the bottom panel of women. To more formally test whether volatility does indeed respond to the business cycle, in Table 1 we report the results of time-series regressions of men's and women's earnings volatility on the aggregate unemployment rate and a trend. Because the time series is interrupted we admit differential intercepts in 1985 and 1995 (1974 is omitted owing to the constant term). The positive and statistically significant coefficient on the unemployment rate in male earnings volatility indicates that it is countercyclical, where a one-percentage point increase in the unemployment rate leads to about a 0.9 standard deviation increase (the elasticity at the means is a small 0.07). For women, on the other hand, earnings volatility is procyclical, with an effect equal to but opposite in sign to that of men. Solon, Barsky, and Parker (1994) showed that wage levels of men are procyclical, but those of women are acyclical (at least statistically), and the reasons for these 
differences were not readily apparent. To our knowledge this is the first such evidence on the cyclicality of women's earnings volatility, and clearly merits additional research for a better understanding of gender differences not only in the cyclicality of earnings levels but also growth.

\section{A. Comparisons with Gottschalk-Moffitt and Shin-Solon}

The measure of volatility in equation (1) differs from other approaches in the literature by its inclusion of the self employed and labor-force nonparticipants, and by focusing on the variance of earnings changes rather than levels with no distinction whether the volatility stems from permanent or transitory components. In this subsection we examine the sensitivity of our measure to some of these inclusion criteria as well as how it relates to alternatives in the literature.

To fix ideas, we begin with the simple decomposition of log earnings into its permanent and transitory components as in Gottschalk and Moffitt (1994), denoted as GM for short,

$$
\ln y_{i t}=\alpha_{t} \mu_{i}+\varphi_{t} \varepsilon_{i t}
$$

where $\mu_{i}$ is permanent earnings, $\varepsilon_{i t}$ is transitory earnings, and $\alpha_{t}$ and $\varphi_{t}$ are time-varying factor loadings on the permanent and transitory components, respectively. Following GM that the factor loadings are equal to 1 in all periods, and that the permanent and transitory components are independent, then the variance of log earnings in (2) is simply (3) $\operatorname{Var}\left(\ln y_{i t}\right)=\sigma_{\mu}^{2}+\sigma_{\varepsilon}^{2}$.

This decomposition in (3) prevails in discussions of how the cross-sectional distribution of earnings has been affected by permanent and transitory volatility in recent decades.

If instead we first difference equation (2) and then take variances we get

$$
\operatorname{Var}\left(\ln y_{i t}-\ln y_{i t-1}\right)=\left(\alpha_{t}-\alpha_{t-1}\right)^{2} \sigma_{\mu}^{2}+\varphi_{t}^{2} \sigma_{\varepsilon}^{2}(t)+\varphi_{t-1}^{2} \sigma_{\varepsilon}^{2}(t-1)
$$


which is the measure adopted by Shin and Solon (2010), referred to as SS hereafter. Notice that because the time-difference in log earnings in the left hand side of (4) is approximately the percent change in earnings levels, there is a close link to our measure in equation (1). The difference is that in (1) we compute the arc percent change, while in (4) SS measure the point percent change. If the denominator in (1) is not too different from the initial earnings level $\left(y_{i t-1}\right)$, then the expressions in (1) and (4) are roughly equal. This suggests that our measure in (1) captures changes to permanent variances via changes in the permanent factor loadings as well as changes in transitory variances from either transitory factor loadings or shocks. As highlighted by SS, because the permanent factor loadings from one year to the next are likely to be similar, in practice much of the variation in our measure is likely to be dominated by the transitory components. Indeed, if we again assume that the factor loadings are equal to 1 , then (4) simplifies to the sum of the current and lagged transitory variance, which was the baseline measure employed by Cameron and Tracy (1998). Though, again, we wish to emphasize that we cannot disentangle the relative contributions of permanent and transitory components in our framework in equation (1) without making further structural assumptions.

[Figure 2 here]

In Figure 2 we present our baseline volatility series along with the volatility series generated by the GM approach in equation (3) and the SS approach in equation (4). Specifically, following GM we regress log earnings on a quadratic in age in each year, and depict the annual residual standard deviation reflecting the left hand side of equation (3). Likewise, following SS we regress the change in log earnings on a quadratic in age in each year, and in this case depict 
the annual residual standard deviation reflecting the left hand side of equation (4). ${ }^{7}$ In both cases we multiply the standard deviation by 100 to place it on a similar scale with our measure from (1). As is evident, among men the levels of volatility from both alternative measures are higher than ours in nearly every year, and the initial increase in volatility from the early 1970s to the mid 1980s is higher (about 25 percent compared to our 15 percent). However, the overall trend of fairly stable volatility after the mid 1980s is roughly similar to our baseline series, the exception being the last few years where both the GM and SS series depict sharp reductions. Among women, the level of volatility is again higher in the GM and SS approach, but there is clear evidence of a secular decline in volatility in women's earnings as in our baseline series.

In Figure 2 we use our sample selection and variable definitions to make the comparisons between GM, SS, and our approach as close as possible. However, there are important distinctions. Our measure admits observations for whom earnings are zero in one year, and nonzero the other. Because GM and SS both utilize log earnings, these observations are necessarily omitted from the GM and SS trends in Figure 2 but not our series. ${ }^{8}$ Likewise, our

\footnotetext{
${ }^{7}$ GM actually use a quartic in age but we found that this has little discernable impact on trend volatility compared to the quadratic. SS report a similar result.

${ }^{8}$ When we use the earnings from year 1 in the denominator, this violates the symmetry property that bounds our volatility estimates between -/+ 200, and our series is then unduly influenced by outliers in the initial period. If we truncate the earnings levels to say a floor of $\$ 5,000$ then taking the point percent change yields estimates similar to GM and SS. That is, the reason the log difference does not have this "problem" is that logs dampen huge effects because the log function is concave, but our measure is not. However, our approach with average earnings in the denominator is an alternative way of ensuring that outliers do not leverage the estimates, but
} 
measure admits observations with negative earnings from self employment, but once again the log transform in the GM and SS approach drops these person years. Hence, in Figure 3 we attempt to place the three alternatives on equal footing by restricting attention to wage and salary workers, dropping those with self employment income or with zero income in any period. Figure 3 shows that the series based on our measure is dampened considerably compared to Figure 1, but that there is general agreement across the three measures that earnings volatility among men has been flat for the past 25 years, and it has been declining among women. That the levels of GM are higher compared to the SS and our measure owes to the fact that GM reflects earnings levels, not changes, and that SS is higher than our measure is most likely due to our use of a two-year average of earnings in the denominator of the arc percent change in (1). ${ }^{9}$

unlike the log function, ours does not break down completely when one of the year's earnings are zero.

${ }^{9}$ Both GM and SS trim workers with earnings in the top and bottom 1 percent of earnings from their sample, and restrict their analysis to men ages 20-59. In Appendix Figure 1 we present the trends from GM and SS measures with these additional restrictions, i.e. we trim the top and bottom 1 percent and focus on men with positive earnings ages 20-59 (white men only in the case of GM). It is clear that the series have fewer high frequency changes, and in the case of men with SS volatility peaks in the mid 1980s. With GM, however, total residual variance continues to increase. Because of the prevalence of the GM decomposition in equation (3) we also show the individual permanent and transitory components. Transitory variance is simply the within variance (see GM’s appendix), and permanent is the difference between total residual variance and transitory. Consistent with GM's results from the PSID, we find in matched CPS that transitory volatility accounts for about 40 percent of the total residual variance in a typical year. 
Our takeaway from Figure 3 is that the GM and SS measures, by restricting the sample to only workers with positive earnings in both periods, understates both level and trends of volatility.

[Figure 3 here]

\section{B. The Role of Employment Transitions on Earnings Volatility}

In this section we explore in greater detail the role of employment transitions in trend volatility, which has been largely ignored in the prior literature. With the influx of large numbers of women into emplotment in recent decades, coupled with labor-force withdrawal of men, the increase in earnings volatility may be due to a compositional change of the workforce, or it may simply reflect increased earnings dispersion of workers (Lemieux 2006). That is, the volatility of earnings depends on the relative role of changes in the extensive margin of entry and exit into employment and the intensive margin of earnings conditional on being a worker. For our purposes, an individual is considered employed if they record any earnings in the previous year. Because we define volatility as the variance of the percent change from one period to the next, there are four possible states of employment between years: $(0,0),(0,1),(1,0)$, and $(1,1)$, where 0 means out of employment and 1 means employed. In Figure 4 we depict trends in mean employment status for men and women for each of the four states. The figure reveals that among men there is a secular trend increase in the $(0,0)$ state, and trend decrease in the $(1,1)$ case, but relatively constant and symmetric transition rates into $(0,1)$ and out of work $(1,0)$. For women, on the other hand, the trend increase in the $(1,1)$ state, and concomitant decrease in $(0,0)$, plateaued in the mid 1990s and actually reversed slightly in the 2000s. Note that the level of the $(0,1)$ probability in the first half of the sample period was higher than in the second half of the sample, which reflects the increasing transition of women into employment and thus the trend toward the higher $(1,1)$ state during the 1970 s and 80 s. 
[Figure 4 here]

To see the possible interaction between the extensive and intensive margins on the unconditional volatility of earnings note that we can write the variance as

$$
V(q)=E\{V(q \mid P)\}+V(E\{q \mid P\}),
$$

where $q$ is the arc percent change in earnings, $P$ is an indicator variable equal to one if an individual is employed, and $E$ is the expectations operator. Equation (5), which expresses volatility as the unconditional variance of the percent change of earnings instead of the standard deviation, is the sum of the expected conditional variance of the percent change and the variance of the conditional mean of the percent change.

With four possible states of employment, this implies that the first term on the right hand side of equation (4) can be expressed as

$V(q \mid P=1,0) * \operatorname{Pr}(P=1,0)+V(q \mid P=1,1) * \operatorname{Pr}(P=1,1)$.

Note that the volatility of nonworkers is zero, and thus the first term of (6) is zero. Also, because the arc percent change equals 200 for all workers in the $(0,1)$ state, and equals - 200 for all workers in the $(1,0)$ state, this means the variance of these two subsamples are also zero since the percent change is a constant for all persons in each group. Consequently, the only term remaining in (6) is the fourth term, which is the conditional variance of two-period workers weighted by the probability of working both periods.

Likewise, we can express the variance of the conditional mean in equation (5) as follows

$\operatorname{Pr}(P=0,1)+(E\{q \mid P=1,0\}-E\{q\})^{2} * \operatorname{Pr}(P=1,0)+(E\{q \mid P=1,1\}-E\{q\})^{2} *$ $\operatorname{Pr}(P=1,1)$. 
Here note that $E\{q \mid P=0,0\}=0$, i.e. the conditional mean of two-period non-workers is zero, but the remaining terms are non-zero. This implies that the unconditional variance in (5) is a function of five terms - the weighted conditional variance in equation (6) plus the four weighted variances from (7) consisting of the squared unconditional mean of two-period non-workers, the variance of the conditional mean of people transitioning into work, the variance of the conditional mean of people exiting work, and the variance of the conditional mean of two-period workers. The four terms from (7) demonstrate that volatility may be driven by compositional changes in the workforce, and the lone remaining term in (6) describes the instability of earnings among continuous workers. Note that GM and SS provide unweighted estimates of the conditional variance in (6), $V(q \mid P=1,1)$, but miss the four terms from equation (7).

[Figures 5-6 here]

In Figures 5-6 we depict the time series of each of the five components in the volatility variance decomposition for individual earnings of men and women, respectively. In the top panel of each figure we depict the conditional variance of two-period workers from equation (6) along with the variance of the conditional mean for the two transition states $(0,1)$ and $(1,0)$. Because the variances of conditional means for the two period work $(1,1)$ and non-work $(0,0)$ states are considerably smaller we present them in the bottom panels of each figure. Also, since the contribution of the variances of the conditional means from the continuous work and non-work states to overall volatility is negligible we restrict attention to the top panels.

In Figure 5 it is clear that male earnings volatility has historically been dominated by the conditional variance of continuous workers (the term from equation (6)), though after the mid 1990s the contribution of the conditional mean variance of men transitioning from work to nonwork $(1,0)$, and from non-work to work $(0,1)$ increases. In Table 2 we present the shares of each 
of the five variance terms to the total volatility (across five-year intervals for ease of exposition). In 1973 the conditional variance of continuous male workers accounted for about 53 percent of the total, but by 2008 it had fallen to about 38 percent, which is not much different than the 31 and 30 percent shares accumulating to men entering and exiting employment. Thus even though the probability of such a transition is small and stable over the period as seen in Figure 4, the contribution to volatility is not, and failure to account for employment transitions distorts the overall level and trend of volatility.

[Table 2 here]

Figure 6 and the bottom half of Table 2 depict the trends in the earnings variance components for women. Here the timing of the story is reversed from that of men. In the 1970s and early 1980s volatility of women's earnings was dominated by those workers transitioning in and out of employment. For example, in 1973 over one-third of the variance was accounted for by each of the variance of conditional means $(0,1$ and 1,0$)$, and under one-quarter to the conditional variance of continuous workers $(1,1)$. By the late 1980 s thru the mid 2000 s the shares across the three components were roughly similar. Although in the last few years variation from transitions have again dominated, the overall trends is one of convergence between men and women, both in terms of the overall levels of volatility but also in the more or less equal shares accruing to continuous workers and those transitioning in and out of employment.

\section{Heterogeneity in Earnings Volatility}

A key advantage of our use of matched CPS data is the large sample sizes relative to the PSID, and thus in this section we examine whether the trend in earnings volatility was widely distributed across education, family structure, and race. 
The vast literature on rising wage inequality seems to be in agreement that the increase was most pronounced in the 1980s and was likely due to a combination of skill-biased technical change favoring skilled workers, falling unionization, and a declining real wage (Katz and Autor 1999; Lemieux 2008), while the inequality growth of the 1990s was most pronounced in the upper tail of the distribution (Piketty and Saez 2003; Autor, et al. 2008). To the extent that part of the rise in inequality is due to increased volatility, the growth in earnings volatility should differ across education group, and be most pronounced among the least skilled in the first half of the sample and most pronounced among the high skilled in the second half. In Figure 7 we depict trends in earnings volatility for men and women with less than a high school education, those with a high school diploma but not college, and those with at least some college. The figure reveals that volatility levels are much higher among high school dropouts for both men and women, but that the rise (decline) in male (female) earnings volatility inequality cuts across education level. However, earnings volatility rose faster among less skilled men compared to high skilled from 1973-1984 (24 versus 6 percent), and then reversed from 1986-2008 (1 versus 21 percent). For men, the timing of this reversal is consistent with the causes of inequality summarized above and detailed in that literature. Among women, the secular decline in volatility appears to be largely concentrated among those with high school or more as the volatility of dropouts shows no strong trend.

[Figure 7 here]

To explore trends in earnings volatility across education groups in more detail we again return to the variance decomposition of equations (6) and (7). Table 3 reports employment transition rates for men and women across the three education groups. From 1973 to 2008 there was a four-fold increase from 9 to 38 percent in the fraction of male high school dropouts 
reporting that they are out employment in both years, while the fraction reporting working both periods fell by nearly half to 45 percent. There was also a secular rise in the fraction entering and exiting employment, though the rates were much lower than the continuous in or out samples. The same basic pattern holds for men with high school or more, though the two period employment rates are higher and rates of non-employment are substantially lower. For women with less than high school the changes in employment transitions, while in the same direction, were much less pronounced than among men with similar education. Unlike men, women with high school or more actually show a secular decline in $(0,0)$ and secular rise in $(1,1)$ employment rates, and declines in $(0,1)$ and $(1,0)$ to levels not too different from men of similar education.

[Tables 3 and 4 here]

In Table 4 we examine how these employment trends interact with the variance components by presenting the shares of each of the five variance terms to the total volatility across education levels. For men overall we saw in Table 2 that the share of volatility accounted by the conditional variance of continuous workers $(1,1)$ fell over time and the share accruing to the variance of the conditional mean increased, especially the variance of those transitioning from employment to non-employment $(1,0)$. Table 4 reveals that this basic pattern holds across the three major education groups of men, although the share levels differ substantively by education with the conditional variance accounting for much less of the total among men who drop out. Among women, Table 2 showed that there was relative stability across the various components over time compared to men, and unlike men the role of the conditional variance of $(1,1)$ workers increased in the share of total volatility. The results by education in Table 4 indicate that the latter trend appears to follow the trends of women with a high school diploma or more as female drop outs have variance share trends more in line with male drop outs . 
[Figure 8 here]

In Figure 8 we depict trends in volatility by marital status (married or unmarried) and race (white or black). Among men, the level and trend of earnings volatility is strikingly different across marital status. The level of volatility among unmarried men was nearly double that of married men in the early 1970s, but this fell to about 50 percent greater by the end of the period both because of rising volatility among married men and falling volatility among unmarried men. When examining the intersection of race and marriage, we see similar patterns among unmarried and married men regardless of race. Although volatility among unmarried black men is higher than unmarried whites early in the sample period, they both fell over time and the levels over the past decade are the same. Likewise, volatility among married black men exceeds that of white men in most years, but both groups experienced sharp increases in volatility through the 1980s. For married women, the secular decline continued through the end of the sample period, suggesting that much of the stability post mid 1980s in Figure 1 owes to unmarried women. There are not substantive differences in female earnings volatility by race across marital status (though the series for married black women is quite volatile owing to smaller sample sizes).

\section{[Tables 5-6 here]}

Tables 5 and 6 repeat the analyses of Tables 3 and 4, but now broken down by marital status. As highlighted in Figure 8, the trends in earnings volatility do not differ substantively by race once we condition on marital status (though some of the levels do), and thus in Tables 5 and 6 we do not make distinctions by race. Table 5 shows that rates of non-employment for two periods have been trending upward for both unmarried and married men, and while the levels are much higher among unmarried men, the rate of change has been faster among married men. On the other hand, the $(1,1)$ employment among unmarried men fell 18 percent (from 74 to 61 
percent) during the sample period, compared to about a 6 percent decline among married men. The biggest change among women was the concurrent decline in $(0,0)$ employment and increase in $(1,1)$ employment among those who were married. Incorporating these employment transitions into the variance decomposition of earnings, Table 6 shows that the trends affecting men who dropped out of high school in Table 4 are broadly similar to those affecting unmarried men-the share accruing to the conditional variance of continuous work fell in relation to the variance of the conditional mean of men exiting employment $(1,0)$. Because the decline in the conditional variance term exceeded the increase in the variance of the conditional mean, total volatility of unmarried men fell. Indeed, the gap in volatility among unmarried and married men narrowed not only because of the decline among unmarried men, but also the increase among married men, especially the higher shares accruing to the variance of conditional means from transitions.

\section{Conclusion}

Our results from matched CPS data show that earnings volatility among men increased from the early 1970s to mid 1980s, while women's volatility fell, and each stabilized thereafter. However, this masks important heterogeneity in volatility levels and trends across education groups and marital status. Moreover, we find that men's earnings volatility is increasingly accounted for by employment transitions, especially exits, while the share of women's volatility accounted for by continuous workers rose, each of which highlights the importance of allowing for periods of non-work in volatility studies. With the aging of the labor force these trends are likely to continue to exert upward pressure on volatility overall.

Our results broadly corroborate those from studies based on the PSID, and to a lesser extent those from the SIPP. Research from both surveys indicated that men's earnings volatility 
peaked in the early 1980s. With the change to every other year survey design after 1997, Gottschalk and Moffitt (2009) urge caution in interpreting volatility trends from the PSID in the 2000s. This, in addition to its large sample sizes that permit more robust analyses by subgroups, makes data from matched CPS an appealing complementary source for future research on this topic. With broad trends in earnings volatility now established across several major survey and administrative data sets, new research is needed on underlying causal factors such as whether the employment transitions leading to higher volatility are voluntary or involuntary, whether trends in total income volatility (and various nonlabor income components) follow similar trends to earnings, as well as to research on the effects of volatility on family and child well being. 


\section{References}

Autor, David H., Lawrence F. Katz, and Melissa S. Kearney. 2008. “Trends in U.S. Wage Inequality: Re-Assessing the Revisionists.” Review of Economics and Statistics 90(2): 300-323.

Blank, Rebecca. 2002. “Evaluating Welfare Reform in the U.S.” Journal of Economic Literature 40(4): 1105-1166.

Bollinger, Christopher, and Barry Hirsch. 2006. "Match Bias from Earnings Imputation in the Current Population Survey: The Case of Imperfect Matching.” Journal of Labor Economics 24(3): 483-520.

Bollinger, Christopher R. and Barry T. Hirsch. 2010. “Is Earnings Nonresponse Ignorable?” IZA Discussion Paper 5347

Burkhauser, Richard, J.S. Butler, Shuaizhang Feng, and Andrew J. Houtenville. 2004. “Long term trends in earnings inequality: what the CPS can tell us.” Economics Letters 82(2): 295-299.

Burkhauser, Richard, Shuaizhang Feng, and Stephen Jenkins. 2007. “Using the P90/P10 Index to Measure US Inequality Trends with Current Population Survey Data: A View from Inside the Census Bureau Vaults.” IZA Discussion Paper 2839.

Cameron, Stephen, and Joseph Tracy. 1998. "Earnings Variability in the United States: An Examination Using Matched-CPS Data,” Mimeo. http://www.newyorkfed.org/research/economists/tracy/earnings_variability.pdf

Celik, Sule, Chinhui Juhn, Kristin McCue, and Jesse Thompson. 2009. “Understanding Earnings Instability: How Important are Employment Fluctuations and Job Changes?” Census CES Working Paper 09-02. 
Dahl, Molly, Thomas DeLeire, and Jonathan Schwabish. 2008. "Year-to-Year Variability in Worker Earnings and in Household Incomes: Estimates from Administrative Data.” http://www.ssc.wisc.edu/ tdeleire/

Dynan, Karen E., Douglas W. Elmendorf, and Daniel E. Sichel. 2008. “The Evolution of Household Income Volatility.” http://www.brookings.edu/ /media/Files/rc/papers/2007/06useconomics_dynan/06usecon omics_dynan.pdf

Dynarski, Susan and Jonathan Gruber. 1997. “Can Families Smooth Variable Earnings?” Brookings Papers on Economic Activity 1, 229-284.

Gittleman, Maury, and Mary Joyce. 1996. “Earnings Mobility and Long-Run Inequality: An Analysis Using Matched CPS Data.” Industrial Relations 35(2): 180-196.

Gottschalk, Peter and Robert Moffitt. 1994. "The Growth of Earnings Instability in the U.S. Labor Market.” Brookings Papers on Economic Activity 1, 217-254.

Gottschalk, Peter, and Robert Moffitt. 2009. “The Rising Instability of U.S. Earnings.” Journal of Economic Perspectives 23(4): 3-24.

Gundersen, Craig, and James P. Ziliak. 2003. “The Role of Food Stamps in Consumption Stabilization,” Journal of Human Resources 38(Supplement): 1051-1079.

Haider, Steven. 2001. “Earnings Instability and Earnings Inequality of Males in the United States: 1967-1991.” Journal of Labor Economics 19(4): 799-836.

Hacker, Jacob S., and Elisabeth Jacobs. 2008. “The Rising Instability of American Family Incomes, 1969-2004: Evidence from the Panel Study of Income Dynamics.” EPI Briefing Paper 213, Economic Policy Institute.

Hotz, V. Joseph, and John Karl Scholz. 2003. “The Earned Income Tax Credit.” In Means-Tested 
Transfer Programs in the United States, Robert Moffitt, ed., The University of Chicago Press and NBER, 141-197.

Jensen, Shane T., and Stephen H. Shore. 2008. "Changes in the Distribution of Income Volatility.” http://arxiv.org/PS_cache/arxiv/pdf/0808/0808.1090v1.pdf.

Juhn, Chinhui, and Kristin, McCue. 2010. “Comparing Measures of Earnings Instability Based on Survey and Administrative Reports.” Census CES Working Paper 10-15.

Katz, Lawrence F., and David H. Autor. 1999. "Changes in the Wage Structure and Earnings Inequality,” in Handbook of Labor Economics, Orley C. Ashenfelter and David Card, eds., Amsterdam: Elsevier.

Keys, Ben. 2008. “Trends in Income and Consumption Volatility, 1970-2000.” In Income Volatility and Food Assistance in the United States, D. Jolliffe and J. P. Ziliak, eds., Kalamazoo, MI: W.E. Upjohn Institute.

Kniesner, Thomas J., and James P. Ziliak. 2002a. “Tax Reform and Automatic Stabilization.” American Economic Review 92(3): 590-612.

Kniesner, Thomas J., and James P. Ziliak. 2002b. “Explicit Versus Implicit Income Insurance.” Journal of Risk and Uncertainty 25(1): 5-20.

Larrimore, Jeff, Richard V. Burkhauser, Shuaizhang Feng, and Laura Zayatz. “Consistent cell means for topcoded incomes in the public use march CPS (1976-2007).” Journal of Economic and Social Measurement 33(2008): 89-128.

Lemieux, Thomas. 2006. “Increasing Residual Wage Inequality: Composition effects, Noisy Data, or Rising Demand for Skill?” American Economic Review 96(3): 461-498.

Lemieux, Thomas. 2008. “The Changing Nature of Wage Inequality.” Journal of Population Economics 21(1): 21-48. 
Piketty, Thomas, and Emmanuel Saez. 2003. "Income Inequality in the United States, 19131998.” Quarterly Journal of Economics 118(1): 1-39.

Shin, Donggyun, and Gary Solon. 2008. “Trends in Men’s Earnings Volatility: What Does the Panel Study of Income Dynamics Show?” NBER Working Papers, 14075.

Solon, Gary, Robert Barsky, and Jonathan Parker. 1994. "Measuring the Cyclicality of Real Wages: How Important is Composition Bias?” Quarterly Journal of Economics 109(1): $1-25$.

Winship, Scott. 2009. “The Very Small Risk Shift: Trends in Family Income Changes.” Unpublished dissertation, Harvard University. http://www.scottwinship.com/dissertation.html

Winship, Scott. 2011. "Economic Instability Trends and Levels across Household Surveys.” Mimeo.

Wooldridge, Jeffrey. 2001. Econometric Analysis of Cross Section and Panel Data. Cambridge, MA: The MIT Press.

Ziliak, James P., and Thomas J. Kniesner. 1998. “The Importance of Sample Attrition in LifeCycle Labor Supply Estimation,” Journal of Human Resources 33(2): 507-530.

Ziliak, James P. 2009. Welfare Reform and its Long Term Consequences for America's Poor. Cambridge, UK: Cambridge University Press. 


\section{Figure 1. Individual Earnings Volatility By Gender}

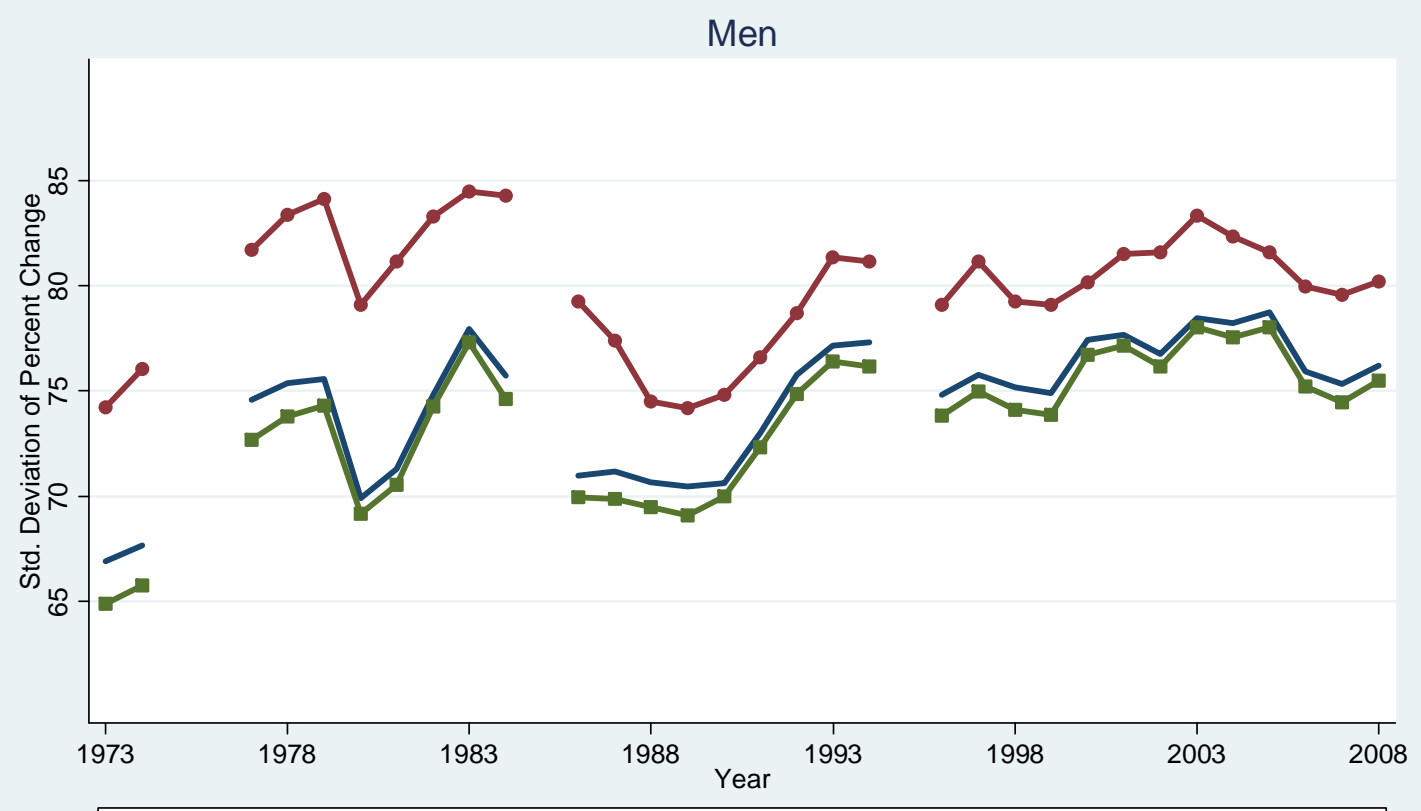

Baseline Series
Baseline Series With Lifecycle Controls on Percent Change

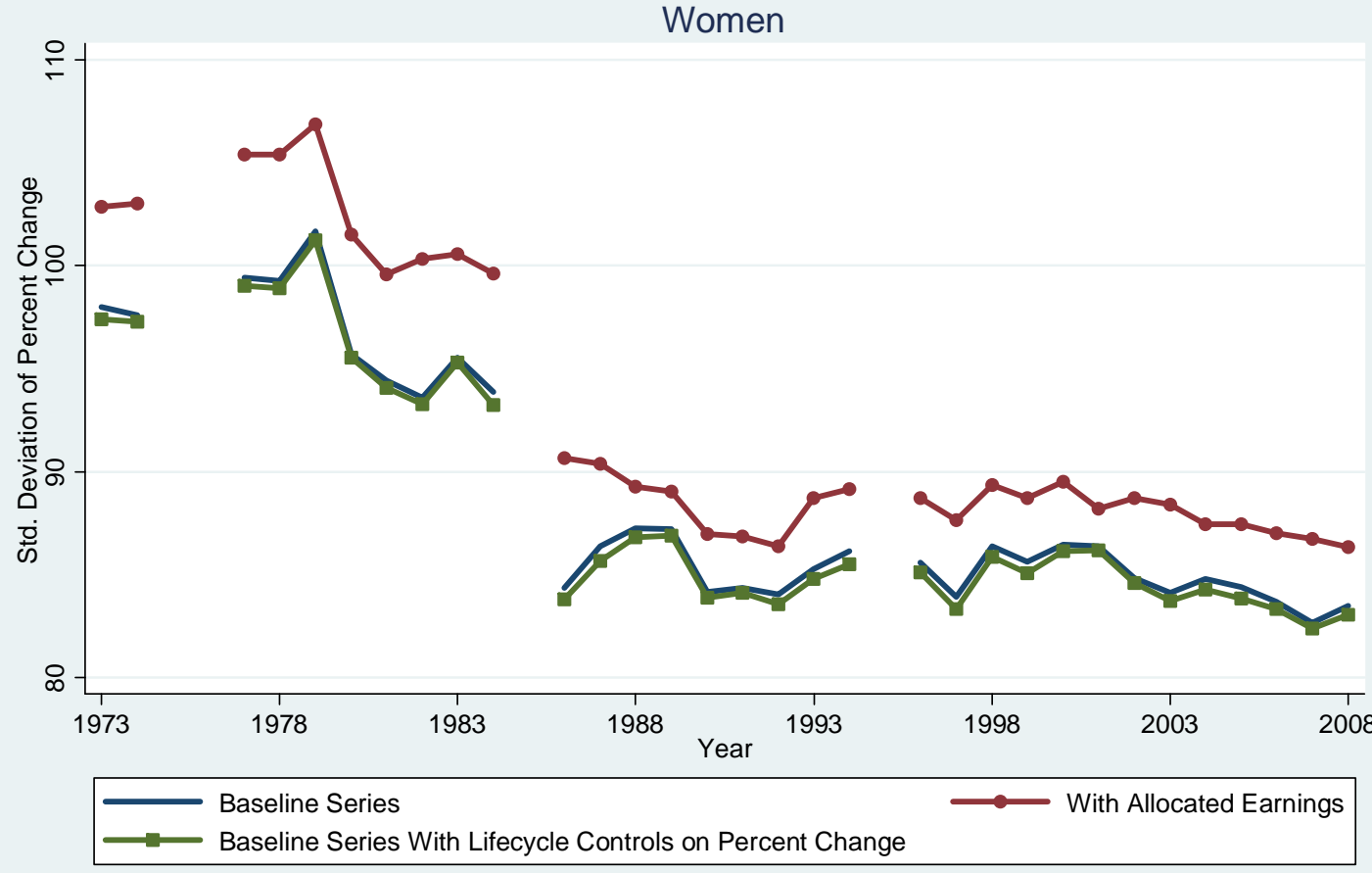


Figure 2. Alternative Measures of Individual Earnings Volatility
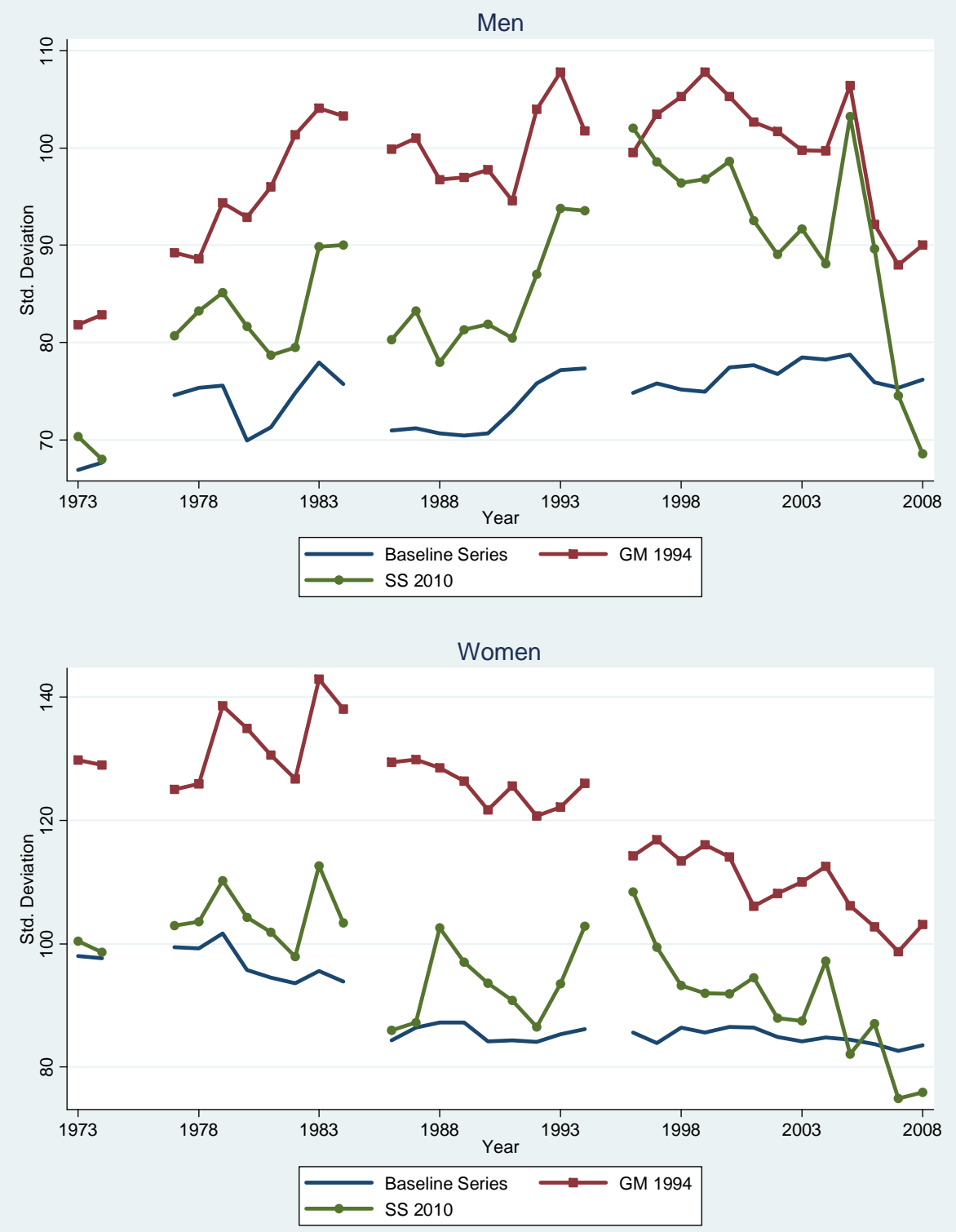
Figure 3. Individual Wage \& Salary Volatility
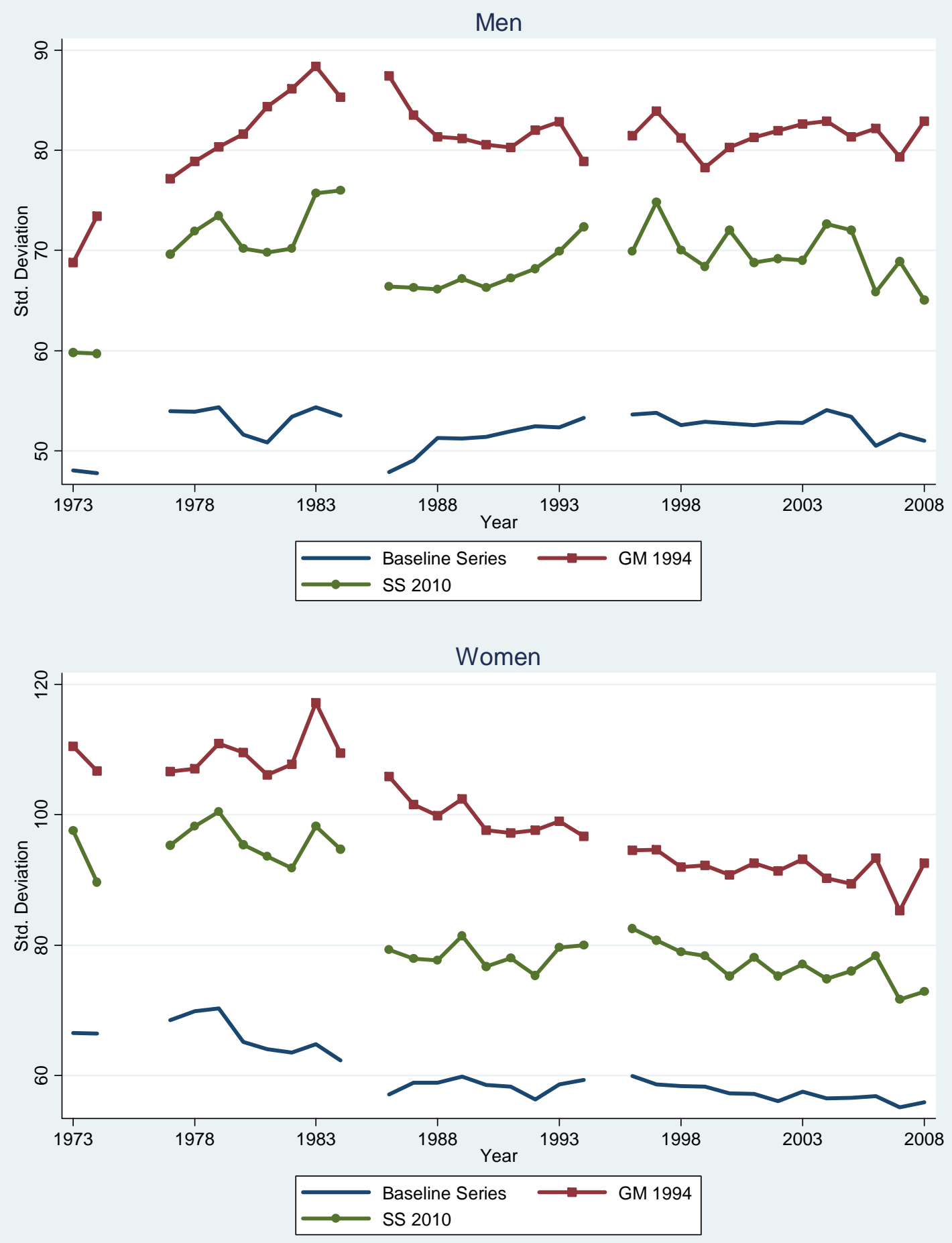


\section{Figure 4. Mean Employment Status}
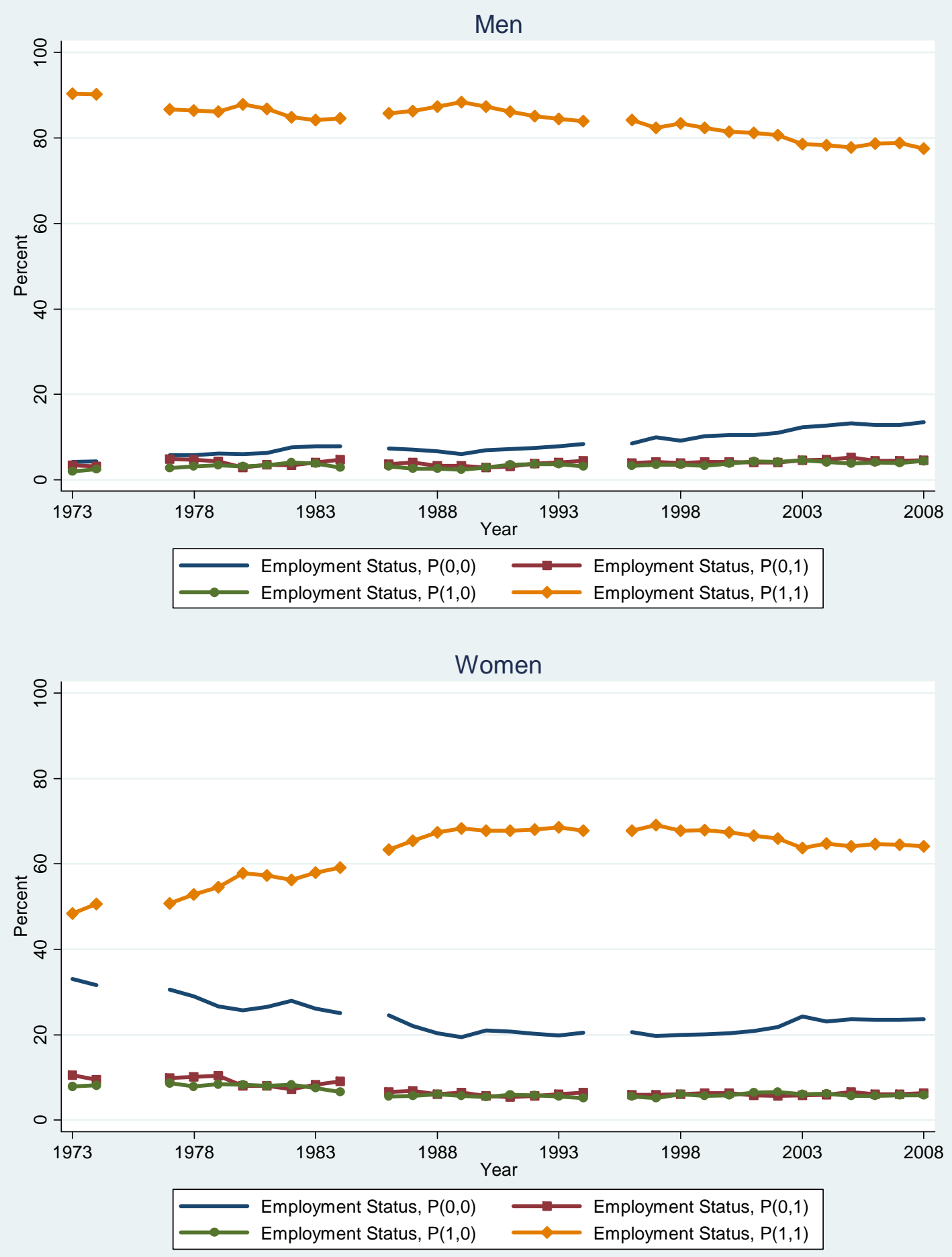
Figure 5. Variance Decomposition of Male Earnings
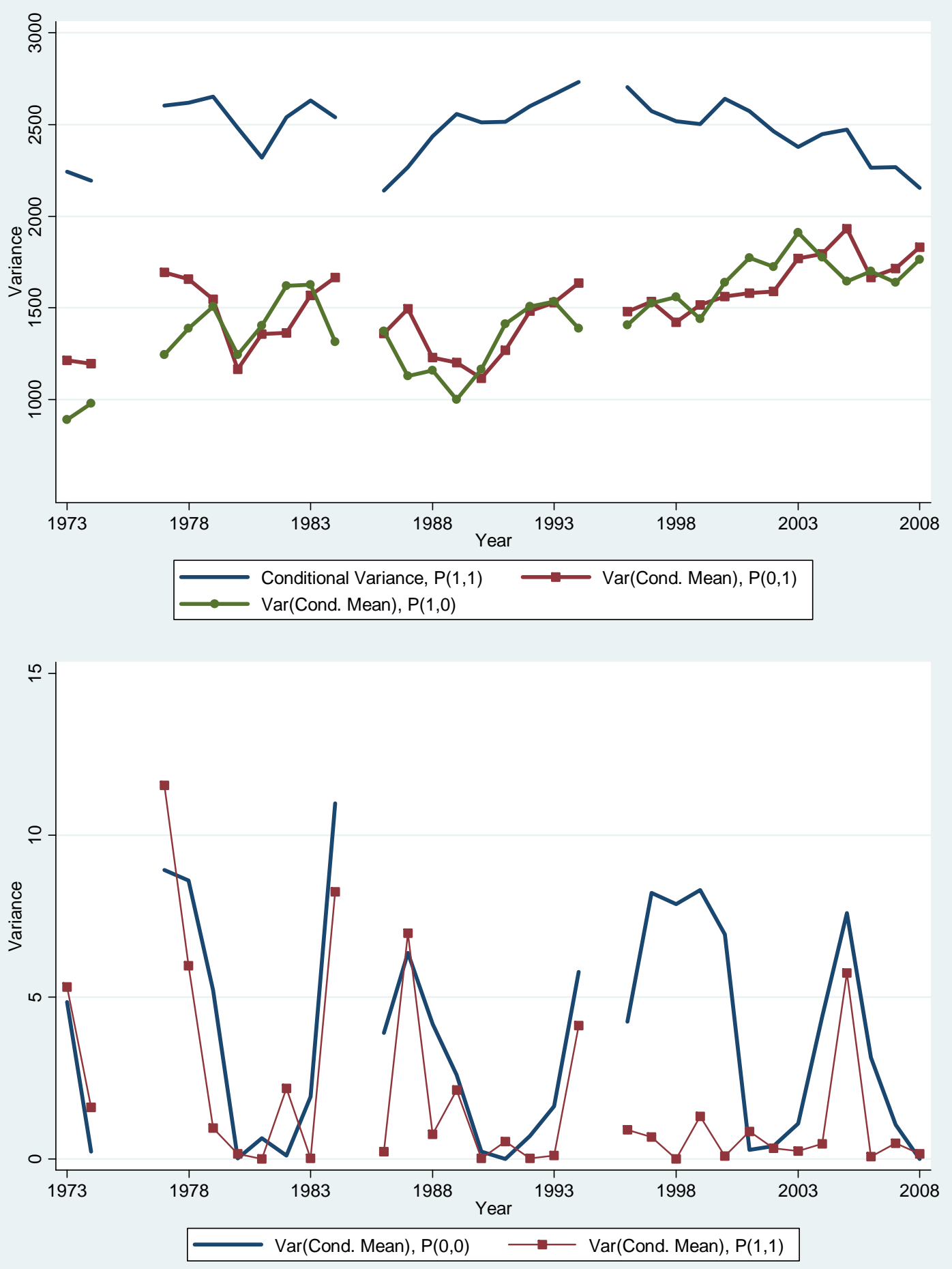
Figure 6. Variance Decomposition of Female Earnings
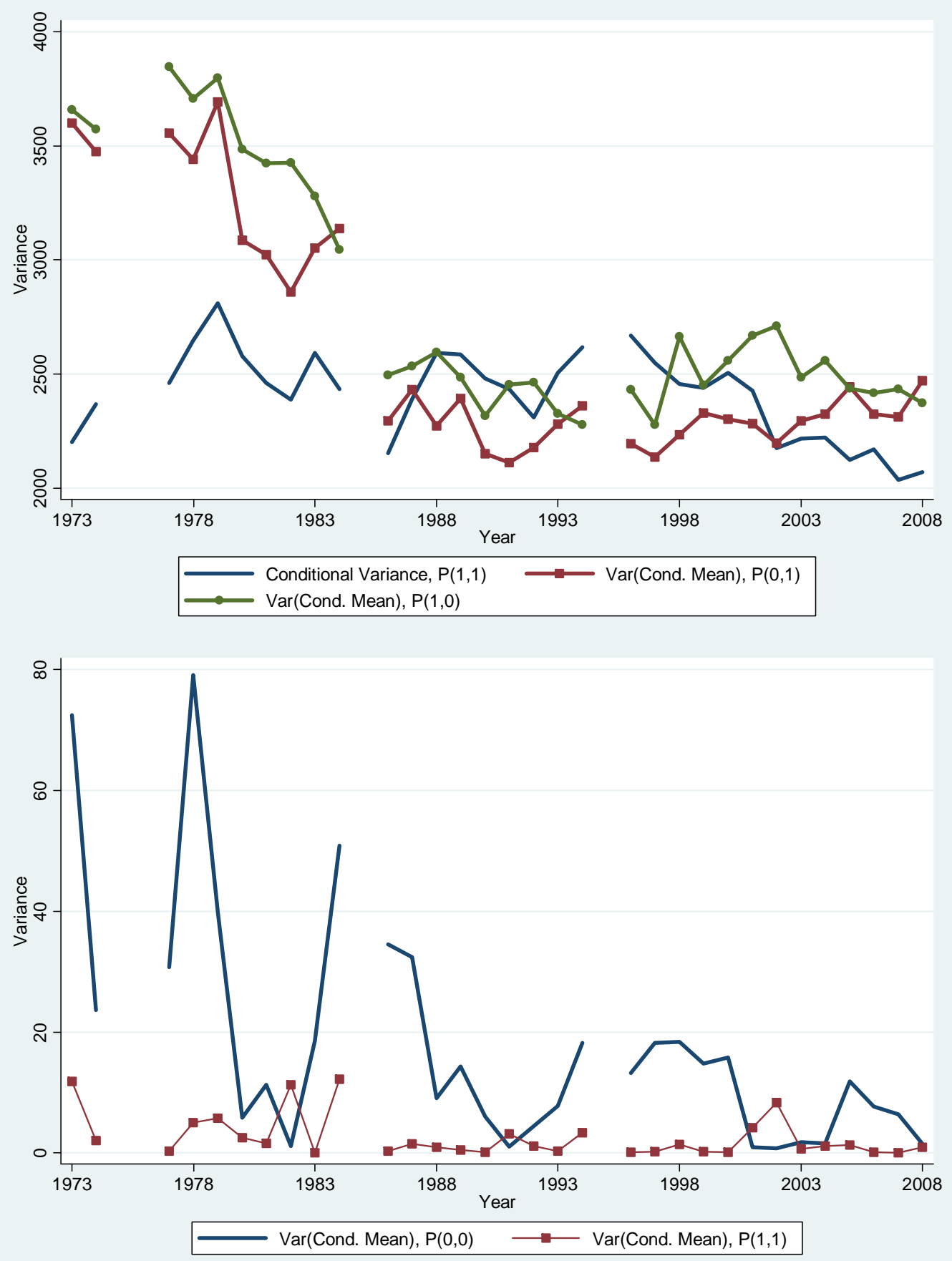
Figure 7. Individual Earnings Volatility By Education
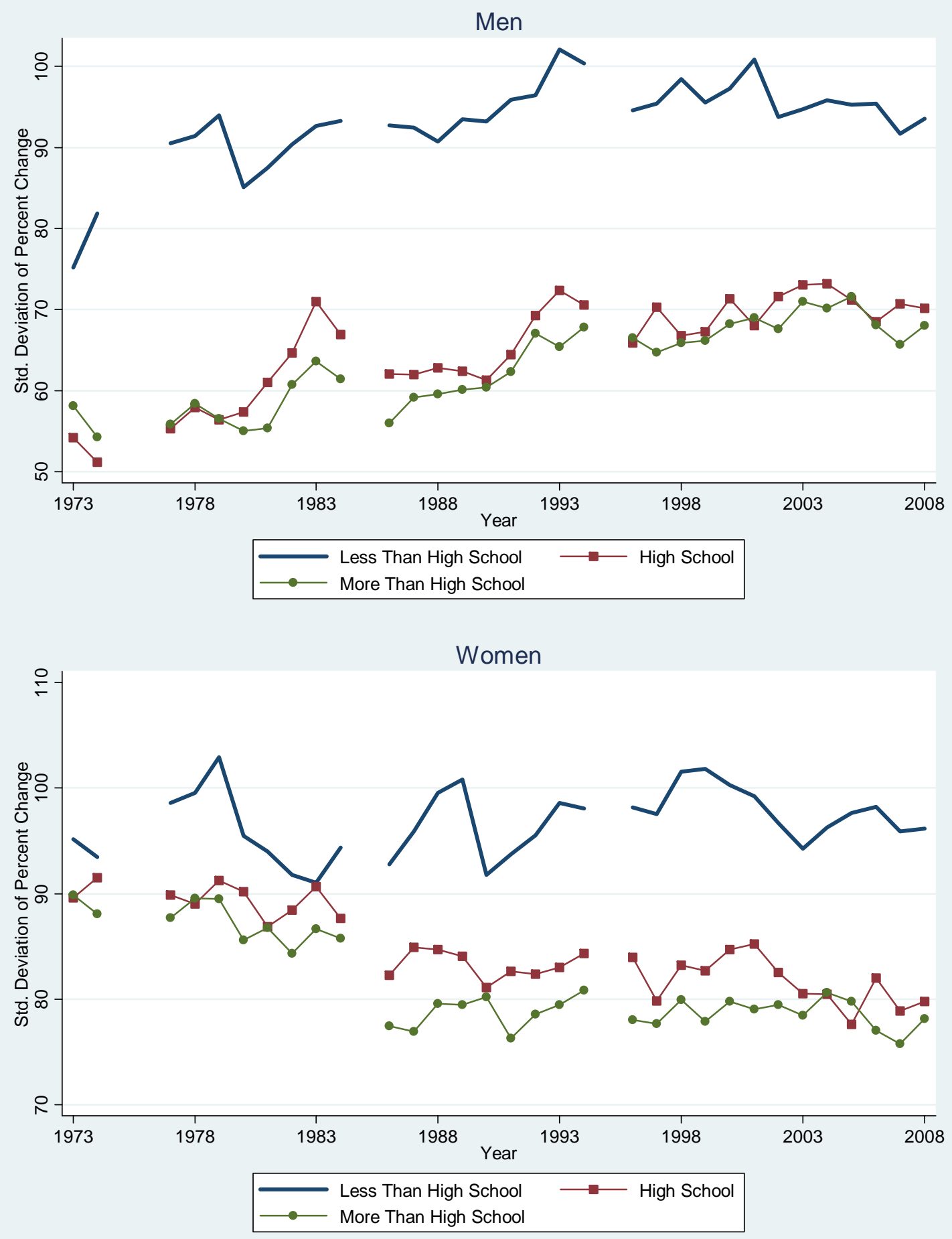
Figure 8. Individual Earnings Volatility By Gender, Status in Families, \& Race
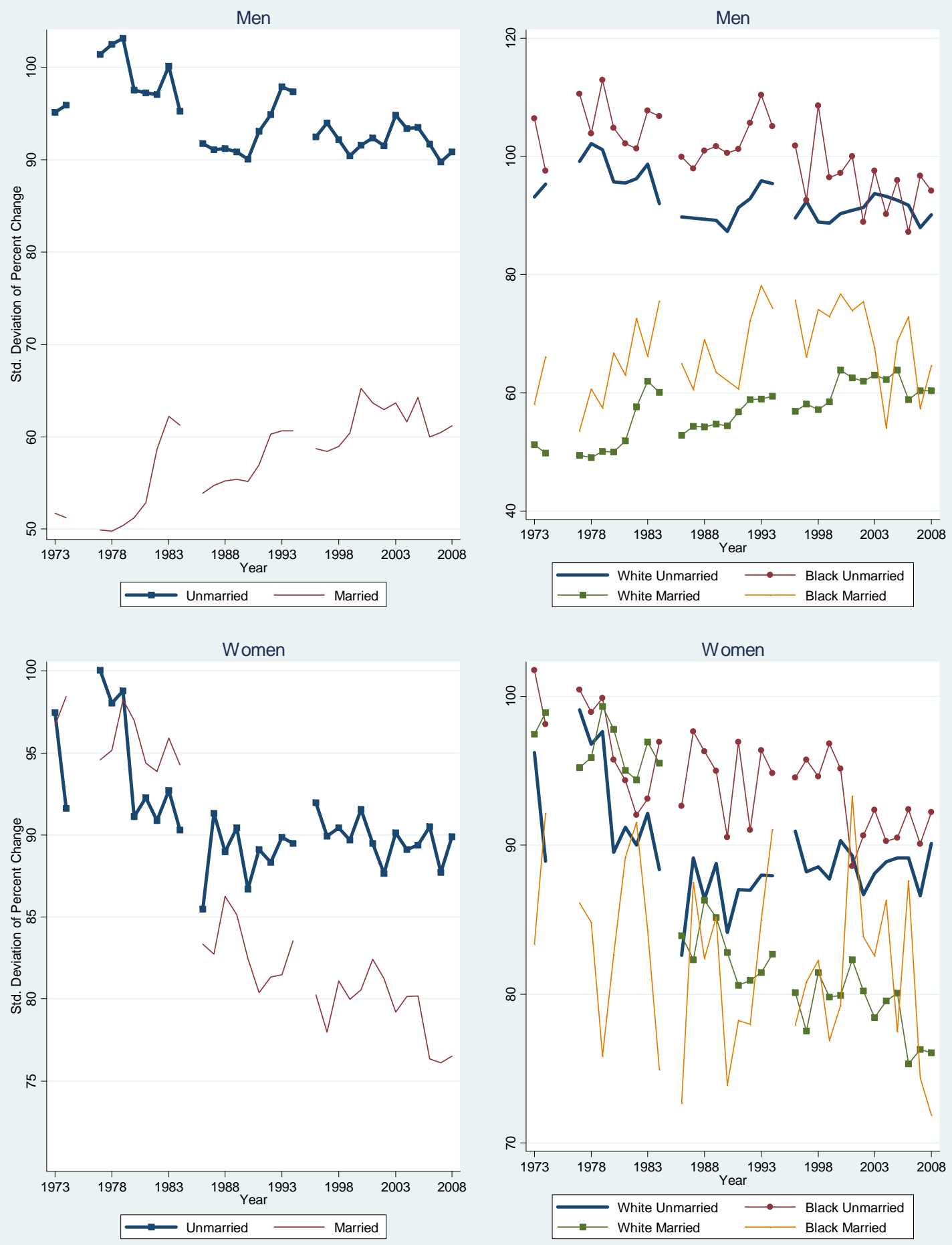


\section{Appendix Figure 1. Individual Total Earnings Volatility Alternative Measures and Sample}
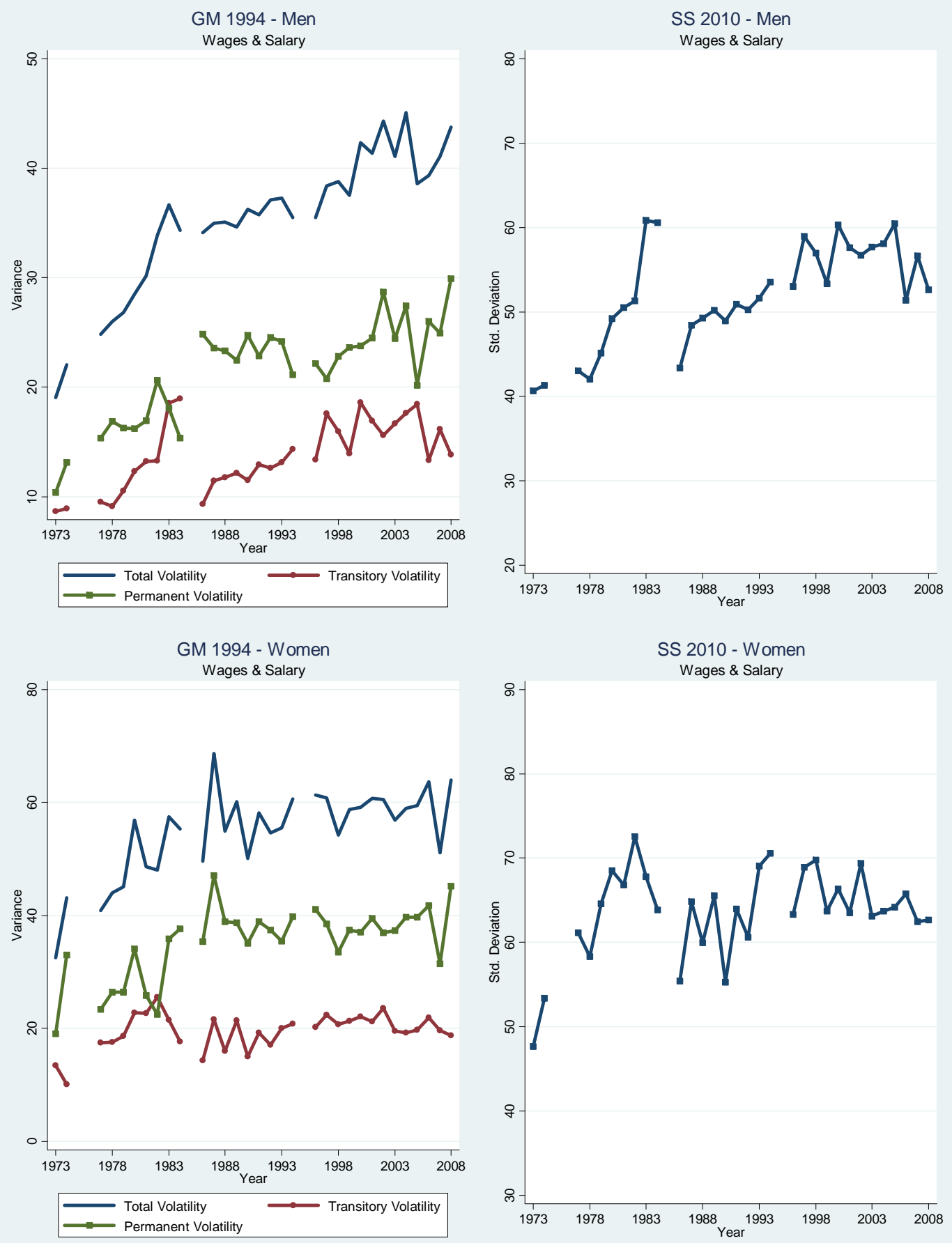
Table 1. Volatility and the Business Cycle

\begin{tabular}{lcc}
\hline & $(1)$ & $(2)$ \\
\hline & Male Earnings & Female Earnings \\
Unemployment & $0.853^{*}$ & $-0.844^{* * *}$ \\
1985 & $(0.430)$ & $(0.283)$ \\
& -2.975 & $-10.520^{* * *}$ \\
1995 & $(1.884)$ & $(1.240)$ \\
& 0.625 & -0.041 \\
Time Trend & $(2.117)$ & $(1.394)$ \\
& $0.337^{* *}$ & -0.145 \\
Constant & $(0.130)$ & $(0.085)$ \\
& $64.528^{* * *}$ & $103.929 * * *$ \\
Observations & $(2.797)$ & $(1.842)$ \\
R-squared & 32 & 32 \\
\hline
\end{tabular}

Standard errors in parentheses. ${ }^{* * *} \mathrm{p}<0.01,{ }^{* *} \mathrm{p}<0.05,{ }^{*} \mathrm{p}<0.10$. 
Table 2. Share of Earnings Variance Decomposition by Component

\begin{tabular}{|c|c|c|c|c|c|}
\hline & $(1)$ & (2) & (3) & (4) & (5) \\
\hline & $\begin{array}{l}\text { Conditional } \\
\text { Variance, } \\
\mathrm{P}(1,1)\end{array}$ & $\begin{array}{c}\text { Variance of } \\
\text { Conditional } \\
\text { Mean, } \\
\mathrm{P}(0,0)\end{array}$ & $\begin{array}{c}\text { Variance of } \\
\text { Conditional } \\
\text { Mean, } \\
\mathrm{P}(0,1)\end{array}$ & $\begin{array}{c}\text { Variance of } \\
\text { Conditional } \\
\text { Mean, } \\
\mathrm{P}(1,0)\end{array}$ & $\begin{array}{l}\text { Variance of } \\
\text { Conditional } \\
\text { Mean, } \\
\mathrm{P}(1,1)\end{array}$ \\
\hline & \multicolumn{4}{|c|}{ Men } & \multirow[b]{2}{*}{0.08} \\
\hline 1973 & 52.89 & 0.10 & 27.19 & 19.74 & \\
\hline 1978 & 46.10 & 0.13 & 29.40 & 24.30 & 0.06 \\
\hline 1983 & 47.87 & 0.03 & 25.63 & 26.47 & 0.00 \\
\hline 1988 & 52.44 & 0.07 & 24.32 & 23.16 & 0.00 \\
\hline 1993 & 49.21 & 0.02 & 25.25 & 25.52 & 0.00 \\
\hline 1998 & 47.74 & 0.11 & 25.12 & 27.02 & 0.01 \\
\hline 2003 & 40.43 & 0.02 & 28.68 & 30.86 & 0.01 \\
\hline 2008 & 38.22 & 0.00 & 31.38 & 30.40 & 0.00 \\
\hline \multicolumn{6}{|c|}{ Women } \\
\hline 1973 & 24.03 & 0.33 & 39.04 & 36.60 & 0.00 \\
\hline 1978 & 26.87 & 0.40 & 36.75 & 35.96 & 0.02 \\
\hline 1983 & 31.11 & 0.11 & 33.81 & 34.94 & 0.02 \\
\hline 1988 & 36.43 & 0.07 & 29.96 & 33.48 & 0.06 \\
\hline 1993 & 37.23 & 0.07 & 31.67 & 31.03 & 0.00 \\
\hline 1998 & 34.49 & 0.16 & 30.57 & 34.69 & 0.10 \\
\hline 2003 & 32.70 & 0.01 & 32.52 & 34.75 & 0.02 \\
\hline 2008 & 30.65 & 0.01 & 35.98 & 33.36 & 0.00 \\
\hline
\end{tabular}

The numbers in the column (1) reflect the share of earnings variance accounted for in the decomposition of equation (6) of the text, while columns (2)-(5) come from equation (7) of the text. 
Table 3. Employment Rates of Men and Women by Education

\begin{tabular}{|c|c|c|c|c|}
\hline & $(1)$ & $(2)$ & $(3)$ & $(4)$ \\
\hline & $\mathrm{P}(0,0)$ & $\mathrm{P}(0,1)$ & $\mathrm{P}(1,0)$ & $\mathrm{P}(1,1)$ \\
\hline & \multicolumn{4}{|c|}{ Men-Less than High School } \\
\hline 1973 & 9.27 & 5.85 & 2.93 & 81.95 \\
\hline 1978 & 14.87 & 8.55 & 5.38 & 71.20 \\
\hline 1983 & 21.27 & 8.05 & 6.69 & 64.00 \\
\hline 1988 & 18.71 & 8.18 & 4.84 & 68.27 \\
\hline 1993 & 23.71 & 11.55 & 6.84 & 57.89 \\
\hline 1998 & 24.63 & 10.70 & 6.83 & 57.85 \\
\hline 2003 & 33.25 & 9.68 & 7.49 & 49.58 \\
\hline \multirow[t]{2}{*}{2008} & 37.79 & 9.97 & 7.15 & 45.09 \\
\hline & \multicolumn{4}{|c|}{ Women-Less than High School } \\
\hline 1973 & 42.66 & 11.14 & 6.93 & 39.27 \\
\hline 1978 & 41.61 & 10.98 & 8.59 & 38.83 \\
\hline 1983 & 47.57 & 9.39 & 6.91 & 36.13 \\
\hline 1988 & 39.30 & 11.31 & 7.83 & 41.55 \\
\hline 1993 & 43.44 & 10.90 & 8.24 & 37.42 \\
\hline 1998 & 42.34 & 12.14 & 8.75 & 36.77 \\
\hline 2003 & 50.29 & 11.28 & 7.07 & 31.36 \\
\hline 2008 & 50.15 & 12.61 & 7.02 & 30.21 \\
\hline
\end{tabular}


Table 3 Continued

\begin{tabular}{|c|c|c|c|c|}
\hline & $(1)$ & $(2)$ & (3) & (4) \\
\hline & $\mathrm{P}(0,0)$ & $\mathrm{P}(0,1)$ & $\mathrm{P}(1,0)$ & $\mathrm{P}(1,1)$ \\
\hline & \multicolumn{4}{|c|}{ Men-High School } \\
\hline 1973 & 2.11 & 1.02 & 1.64 & 95.23 \\
\hline 1978 & 2.69 & 1.68 & 1.59 & 94.04 \\
\hline 1983 & 4.17 & 2.48 & 2.92 & 90.43 \\
\hline 1988 & 4.48 & 1.61 & 1.99 & 91.92 \\
\hline 1993 & 5.72 & 2.18 & 3.44 & 88.66 \\
\hline 1998 & 6.86 & 2.33 & 2.74 & 88.07 \\
\hline 2003 & 9.64 & 2.92 & 4.13 & 83.31 \\
\hline \multirow[t]{2}{*}{2008} & 11.75 & 2.95 & 4.47 & 80.83 \\
\hline & \multicolumn{4}{|c|}{ Women-High School } \\
\hline 1973 & 35.20 & 7.70 & 7.47 & 49.63 \\
\hline 1978 & 30.04 & 8.45 & 5.93 & 55.57 \\
\hline 1983 & 25.21 & 6.64 & 7.66 & 60.50 \\
\hline 1988 & 20.13 & 5.31 & 6.14 & 68.42 \\
\hline 1993 & 21.13 & 5.61 & 5.41 & 67.85 \\
\hline 1998 & 21.62 & 5.24 & 5.60 & 67.53 \\
\hline 2003 & 24.87 & 4.18 & 6.30 & 64.65 \\
\hline 2008 & 26.39 & 5.04 & 6.07 & 62.49 \\
\hline
\end{tabular}


Table 3 Continued

\begin{tabular}{|c|c|c|c|c|}
\hline & $(1)$ & $(2)$ & (3) & $(4)$ \\
\hline & $\mathrm{P}(0,0)$ & $\mathrm{P}(0,1)$ & $\mathrm{P}(1,0)$ & $\mathrm{P}(1,1)$ \\
\hline & \multicolumn{4}{|c|}{ Men-More than High School } \\
\hline 1973 & 1.89 & 2.19 & 1.09 & 94.83 \\
\hline 1978 & 1.97 & 2.23 & 1.43 & 94.36 \\
\hline 1983 & 2.97 & 1.58 & 2.44 & 93.01 \\
\hline 1988 & 2.46 & 1.52 & 1.78 & 94.24 \\
\hline 1993 & 3.59 & 2.02 & 2.22 & 92.17 \\
\hline 1998 & 4.38 & 1.78 & 2.58 & 91.26 \\
\hline 2003 & 5.84 & 2.91 & 3.45 & 87.80 \\
\hline \multirow[t]{2}{*}{2008} & 6.04 & 2.73 & 3.13 & 88.10 \\
\hline & \multicolumn{4}{|c|}{ Women-More than High School } \\
\hline 1973 & 23.44 & 8.07 & 6.24 & 62.25 \\
\hline 1978 & 20.54 & 7.16 & 6.24 & 66.05 \\
\hline 1983 & 14.35 & 5.57 & 5.26 & 74.82 \\
\hline 1988 & 11.46 & 3.63 & 4.89 & 80.01 \\
\hline 1993 & 11.36 & 4.38 & 4.35 & 79.91 \\
\hline 1998 & 11.88 & 3.98 & 5.35 & 78.79 \\
\hline 2003 & 16.63 & 4.47 & 5.03 & 73.87 \\
\hline 2008 & 15.62 & 4.80 & 4.91 & 74.66 \\
\hline
\end{tabular}


Table 4. Share of Earnings Variance Decomposition by Component and Education

Conditional Variance of Variance of Variance of Variance of Variance, Conditional Conditional Conditional Conditional $\mathrm{P}(1,1) \quad$ Mean, Mean, Mean, Mean, $\mathrm{P}(0,0) \quad \mathrm{P}(0,1) \quad \mathrm{P}(1,0) \quad \mathrm{P}(1,1)$

\begin{tabular}{|c|c|c|c|c|c|}
\hline & & PIII & $P(1)$ & 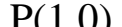 & \\
\hline \multirow[b]{2}{*}{1973} & \multicolumn{4}{|c|}{ Men—Less than High School } & \multirow[b]{2}{*}{0.20} \\
\hline & 40.11 & 0.40 & 35.23 & 24.06 & \\
\hline 1978 & 34.91 & 0.49 & 34.40 & 30.16 & 0.04 \\
\hline 1983 & 31.81 & 0.10 & 35.41 & 32.67 & 0.01 \\
\hline 1988 & 38.71 & 0.41 & 33.54 & 27.26 & 0.08 \\
\hline 1993 & 30.99 & 0.47 & 38.23 & 30.13 & 0.19 \\
\hline 1998 & 29.10 & 0.74 & 36.97 & 33.19 & 0.01 \\
\hline 2003 & 24.18 & 0.24 & 40.24 & 35.33 & 0.01 \\
\hline \multirow[t]{2}{*}{2008} & 22.15 & 0.18 & 42.68 & 34.88 & 0.11 \\
\hline & \multicolumn{4}{|c|}{ Women—Less than High School } & \\
\hline 21.77 & 21.77 & 0.76 & 42.03 & 35.44 & 0.00 \\
\hline 21.09 & 21.09 & 0.59 & 39.23 & 38.92 & 0.16 \\
\hline 21.93 & 21.93 & 0.59 & 41.13 & 36.29 & 0.06 \\
\hline 23.81 & 23.81 & 0.59 & 39.49 & 36.10 & 0.01 \\
\hline 22.14 & 22.14 & 0.37 & 41.66 & 35.83 & 0.00 \\
\hline 19.12 & 19.12 & 1.10 & 39.70 & 39.74 & 0.34 \\
\hline 18.88 & 18.88 & 0.76 & 45.13 & 35.22 & 0.01 \\
\hline 16.64 & 16.64 & 0.85 & 47.96 & 34.33 & 0.21 \\
\hline
\end{tabular}

The numbers in the column (1) reflect the share of earnings variance accounted for in the decomposition of equation (6) of the text, while columns (2)-(5) come from equation (7) of the text. 
Table 4 Continued

\begin{tabular}{|c|c|c|c|c|c|}
\hline & (1) & $(2)$ & (3) & $(4)$ & $(5)$ \\
\hline & $\begin{array}{c}\text { Conditional } \\
\text { Variance, } \\
\mathrm{P}(1,1)\end{array}$ & $\begin{array}{c}\text { Variance of } \\
\text { Conditional } \\
\text { Mean, } \\
\mathrm{P}(0,0)\end{array}$ & $\begin{array}{c}\text { Variance of } \\
\text { Conditional } \\
\text { Mean, } \\
\mathrm{P}(0,1)\end{array}$ & $\begin{array}{c}\text { Variance of } \\
\text { Conditional } \\
\text { Mean, } \\
\mathrm{P}(1,0)\end{array}$ & $\begin{array}{c}\text { Variance of } \\
\text { Conditional } \\
\text { Mean, } \\
\mathrm{P}(1,1)\end{array}$ \\
\hline \multicolumn{6}{|c|}{ Men-High School } \\
\hline 1973 & 63.42 & 0.01 & 13.40 & 23.10 & 0.07 \\
\hline 1978 & 60.99 & 0.04 & 18.72 & 20.25 & 0.00 \\
\hline 1983 & 57.52 & 0.01 & 18.45 & 24.00 & 0.03 \\
\hline 1988 & 63.27 & 0.02 & 15.65 & 21.03 & 0.03 \\
\hline 1993 & 57.75 & 0.01 & 16.17 & 25.95 & 0.13 \\
\hline 1998 & 55.20 & 0.02 & 19.02 & 25.72 & 0.05 \\
\hline 2003 & 46.86 & 0.00 & 21.59 & 31.39 & 0.16 \\
\hline 2008 & 40.83 & 0.07 & 24.20 & 34.78 & 0.12 \\
\hline \multicolumn{6}{|c|}{ Women-High School } \\
\hline 1973 & 24.96 & 0.09 & 36.75 & 38.12 & 0.07 \\
\hline 1978 & 28.10 & 0.49 & 37.94 & 33.47 & 0.00 \\
\hline 1983 & 31.26 & 0.00 & 31.06 & 37.55 & 0.13 \\
\hline 1988 & 36.57 & 0.01 & 28.57 & 34.73 & 0.12 \\
\hline 1993 & 37.71 & 0.06 & 30.33 & 31.87 & 0.02 \\
\hline 1998 & 37.06 & 0.08 & 28.77 & 33.98 & 0.12 \\
\hline 2003 & 35.25 & 0.02 & 26.35 & 38.09 & 0.29 \\
\hline 2008 & 30.29 & 0.02 & 32.43 & 37.22 & 0.03 \\
\hline
\end{tabular}

The numbers in the column (1) reflect the share of earnings variance accounted for in the decomposition of equation (6) of the text, while columns (2)-(5) come from equation (7) of the text. 
Table 4 Continued

\begin{tabular}{|c|c|c|c|c|c|}
\hline & $(1)$ & $(2)$ & $(3)$ & $(4)$ & (5) \\
\hline & $\begin{array}{l}\text { Conditional } \\
\text { Variance, } \\
\text { P(1,1) }\end{array}$ & $\begin{array}{l}\text { Variance of } \\
\text { Conditional } \\
\text { Mean, } \\
\mathrm{P}(0,0)\end{array}$ & $\begin{array}{l}\text { Variance of } \\
\text { Conditional } \\
\text { Mean, } \\
\mathrm{P}(0,1)\end{array}$ & $\begin{array}{c}\text { Variance of } \\
\text { Conditional } \\
\text { Mean, } \\
\mathrm{P}(1,0)\end{array}$ & $\begin{array}{c}\text { Variance of } \\
\text { Conditional } \\
\text { Mean, } \\
\text { P(1,1) }\end{array}$ \\
\hline \multicolumn{6}{|c|}{ Men-More than High School } \\
\hline 1973 & 62.04 & 0.04 & 23.82 & 14.01 & 0.10 \\
\hline 1978 & 57.62 & 0.03 & 24.32 & 17.99 & 0.04 \\
\hline 1983 & 60.03 & 0.00 & 15.25 & 24.62 & 0.09 \\
\hline 1988 & 62.57 & 0.02 & 16.29 & 21.10 & 0.02 \\
\hline 1993 & 62.11 & 0.01 & 16.57 & 21.29 & 0.02 \\
\hline 1998 & 60.37 & 0.04 & 14.73 & 24.75 & 0.12 \\
\hline 2003 & 49.90 & 0.00 & 22.40 & 27.67 & 0.03 \\
\hline 2008 & 49.37 & 0.00 & 23.88 & 26.74 & 0.01 \\
\hline \multicolumn{6}{|c|}{ Women-More than High School } \\
\hline 1973 & 30.02 & 0.18 & 35.81 & 33.99 & 0.00 \\
\hline 1978 & 33.24 & 0.14 & 33.18 & 33.44 & 0.01 \\
\hline 1983 & 44.02 & 0.08 & 26.64 & 29.24 & 0.02 \\
\hline 1988 & 46.83 & 0.02 & 21.61 & 31.35 & 0.20 \\
\hline 1993 & 45.72 & 0.03 & 26.45 & 27.80 & 0.01 \\
\hline 1998 & 41.90 & 0.04 & 23.74 & 34.07 & 0.25 \\
\hline 2003 & 38.64 & 0.00 & 28.67 & 32.65 & 0.03 \\
\hline 2008 & 37.19 & 0.00 & 31.35 & 31.46 & 0.00 \\
\hline
\end{tabular}

The numbers in the column (1) reflect the share of earnings variance accounted for in the decomposition of equation (6) of the text, while columns (2)-(5) come from equation (7) of the text. 
Table 5. Employment Rates of Men and Women by Marital Status

\begin{tabular}{|c|c|c|c|c|}
\hline & (1) & (2) & (3) & (4) \\
\hline & $\mathrm{P}(0,0)$ & $\mathrm{P}(0,1)$ & $\mathrm{P}(1,0)$ & $P(1,1)$ \\
\hline & \multicolumn{4}{|c|}{ Unmarried Men } \\
\hline 1973 & 11.65 & 10.53 & 3.97 & 73.86 \\
\hline 1978 & 12.13 & 11.86 & 5.92 & 70.09 \\
\hline 1983 & 17.07 & 9.53 & 7.60 & 65.80 \\
\hline 1988 & 12.41 & 7.87 & 4.82 & 74.90 \\
\hline 1993 & 14.54 & 9.17 & 6.36 & 69.93 \\
\hline 1998 & 16.43 & 7.99 & 6.29 & 69.30 \\
\hline 2003 & 22.29 & 8.90 & 7.37 & 61.44 \\
\hline \multirow[t]{2}{*}{2008} & 23.81 & 8.44 & 6.75 & 61.01 \\
\hline & \multicolumn{4}{|c|}{ Married Men } \\
\hline 1973 & 1.75 & 0.88 & 1.36 & 96.01 \\
\hline 1978 & 2.78 & 0.87 & 1.38 & 94.96 \\
\hline 1983 & 3.70 & 1.39 & 1.97 & 92.93 \\
\hline 1988 & 3.70 & 0.94 & 1.52 & 93.84 \\
\hline 1993 & 4.38 & 1.18 & 2.23 & 92.22 \\
\hline 1998 & 4.56 & 1.26 & 1.83 & 92.35 \\
\hline 2003 & 5.34 & 1.41 & 2.61 & 90.64 \\
\hline 2008 & 5.75 & 1.64 & 2.61 & 90.00 \\
\hline
\end{tabular}


Table 5 Continued

\begin{tabular}{|c|c|c|c|c|}
\hline & $(1)$ & $(2)$ & $(3)$ & (4) \\
\hline & $\mathrm{P}(0,0)$ & $\mathrm{P}(0,1)$ & $\mathrm{P}(1,0)$ & $\mathrm{P}(1,1)$ \\
\hline & \multicolumn{4}{|c|}{ Unmarried Women } \\
\hline 1973 & 18.23 & 12.80 & 5.36 & 63.62 \\
\hline 1978 & 21.12 & 10.65 & 6.41 & 61.81 \\
\hline 1983 & 23.74 & 9.58 & 6.00 & 60.68 \\
\hline 1988 & 16.83 & 7.93 & 5.31 & 69.92 \\
\hline 1993 & 18.94 & 7.78 & 5.79 & 67.50 \\
\hline 1998 & 19.35 & 8.14 & 5.82 & 66.69 \\
\hline 2003 & 24.10 & 8.26 & 6.15 & 61.49 \\
\hline \multirow[t]{2}{*}{2008} & 23.86 & 8.37 & 6.32 & 61.45 \\
\hline & \multicolumn{4}{|c|}{ Married Women } \\
\hline 1973 & 39.27 & 9.69 & 8.71 & 42.33 \\
\hline 1978 & 34.56 & 9.14 & 7.80 & 48.50 \\
\hline 1983 & 27.88 & 7.41 & 8.25 & 56.47 \\
\hline 1988 & 22.37 & 5.15 & 6.46 & 66.01 \\
\hline 1993 & 20.56 & 5.06 & 5.36 & 69.02 \\
\hline 1998 & 20.56 & 4.79 & 6.09 & 68.55 \\
\hline 2003 & 24.90 & 4.39 & 5.98 & 64.73 \\
\hline 2008 & 23.98 & 4.89 & 5.31 & 65.82 \\
\hline
\end{tabular}


Table 6. Share of Earnings Variance Decomposition by Component and Marital Status

\begin{tabular}{|c|c|c|c|c|c|}
\hline & $(1)$ & $(2)$ & (3) & $(4)$ & $(5)$ \\
\hline & $\begin{array}{c}\text { Conditional } \\
\text { Variance, } \\
\text { P(1,1) }\end{array}$ & $\begin{array}{c}\text { Variance of } \\
\text { Conditional } \\
\text { Mean, } \\
\mathrm{P}(0,0)\end{array}$ & $\begin{array}{c}\text { Variance of } \\
\text { Conditional } \\
\text { Mean, } \\
\text { P(0,1) }\end{array}$ & $\begin{array}{c}\text { Variance of } \\
\text { Conditional } \\
\text { Mean, } \\
\text { P(1,0) }\end{array}$ & $\begin{array}{c}\text { Variance of } \\
\text { Conditional } \\
\text { Mean, } \\
\mathrm{P}(1,1)\end{array}$ \\
\hline \multicolumn{6}{|c|}{ Unmarried Men } \\
\hline 1973 & 41.92 & 1.34 & 32.75 & 23.66 & 0.33 \\
\hline 1978 & 36.39 & 1.08 & 32.43 & 29.99 & 0.10 \\
\hline 1983 & 32.35 & 0.26 & 33.34 & 34.05 & 0.00 \\
\hline 1988 & 40.74 & 0.49 & 31.04 & 27.70 & 0.03 \\
\hline 1993 & 36.10 & 0.23 & 33.74 & 29.87 & 0.06 \\
\hline 1998 & 33.31 & 0.50 & 32.05 & 34.11 & 0.03 \\
\hline 2003 & 27.86 & 0.13 & 36.81 & 35.20 & 0.00 \\
\hline 2008 & 26.66 & 0.08 & 38.80 & 34.43 & 0.04 \\
\hline \multicolumn{6}{|c|}{ Married Men } \\
\hline 1973 & 66.50 & 0.01 & 12.66 & 20.79 & 0.05 \\
\hline 1978 & 63.76 & 0.00 & 13.65 & 22.53 & 0.05 \\
\hline 1983 & 65.88 & 0.00 & 13.93 & 20.15 & 0.04 \\
\hline 1988 & 68.75 & 0.00 & 11.13 & 20.05 & 0.06 \\
\hline 1993 & 66.93 & 0.00 & 10.14 & 22.78 & 0.14 \\
\hline 1998 & 68.49 & 0.01 & 11.63 & 19.81 & 0.06 \\
\hline 2003 & 60.41 & 0.00 & 14.21 & 25.24 & 0.14 \\
\hline 2008 & 56.37 & 0.02 & 17.11 & 26.43 & 0.08 \\
\hline
\end{tabular}

The numbers in the column (1) reflect the share of earnings variance accounted for in the decomposition of equation (6) of the text, while columns (2)-(5) come from equation (7) of the text. 
Table 6 Continued

\begin{tabular}{|c|c|c|c|c|c|}
\hline & $(1)$ & $(2)$ & $(3)$ & $(4)$ & (5) \\
\hline & $\begin{array}{l}\text { Conditional } \\
\text { Variance, } \\
\text { P(1,1) }\end{array}$ & $\begin{array}{l}\text { Variance of } \\
\text { Conditional } \\
\text { Mean, } \\
\text { P(0,0) }\end{array}$ & $\begin{array}{l}\text { Variance of } \\
\text { Conditional } \\
\text { Mean, } \\
\text { P(0,1) }\end{array}$ & $\begin{array}{l}\text { Variance of } \\
\text { Conditional } \\
\text { Mean, } \\
\text { P(1,0) }\end{array}$ & $\begin{array}{c}\text { Variance of } \\
\text { Conditional } \\
\text { Mean, } \\
\text { P(1,1) }\end{array}$ \\
\hline \multicolumn{6}{|c|}{ Unmarried Women } \\
\hline 1973 & 29.13 & 1.51 & 39.37 & 29.66 & 0.33 \\
\hline 1978 & 30.91 & 1.28 & 34.28 & 33.53 & 0.01 \\
\hline 1983 & 28.97 & 0.70 & 37.77 & 32.55 & 0.02 \\
\hline 1988 & 34.30 & 0.42 & 34.37 & 30.90 & 0.02 \\
\hline 1993 & 33.84 & 0.24 & 34.81 & 31.09 & 0.01 \\
\hline 1998 & 32.47 & 0.62 & 33.61 & 33.28 & 0.01 \\
\hline 2003 & 29.59 & 0.19 & 37.45 & 32.74 & 0.03 \\
\hline 2008 & 27.99 & 0.11 & 38.79 & 33.04 & 0.06 \\
\hline \multicolumn{6}{|c|}{ Married Women } \\
\hline 1973 & 21.69 & 0.04 & 39.32 & 38.94 & 0.00 \\
\hline 1978 & 25.36 & 0.12 & 38.14 & 36.39 & 0.00 \\
\hline 1983 & 32.16 & 0.00 & 31.31 & 36.43 & 0.10 \\
\hline 1988 & 37.79 & 0.00 & 27.07 & 34.98 & 0.17 \\
\hline 1993 & 39.59 & 0.01 & 29.04 & 31.32 & 0.03 \\
\hline 1998 & 36.29 & 0.01 & 27.57 & 35.90 & 0.22 \\
\hline 2003 & 34.63 & 0.01 & 28.07 & 37.13 & 0.16 \\
\hline 2008 & 32.93 & 0.00 & 33.26 & 33.80 & 0.00 \\
\hline
\end{tabular}

The numbers in the column (1) reflect the share of earnings variance accounted for in the decomposition of equation (6) of the text, while columns (2)-(5) come from equation (7) of the text. 
Appendix Table 1: Number and Rate of Merges Per Year by $2^{\text {nd }}$ Year of CPS. CY 1973-2008

\begin{tabular}{|c|c|c|c|c|c|c|}
\hline Year & $\begin{array}{c}\text { \# Merged CPS } \\
\text { Observations }\end{array}$ & $\begin{array}{c}\text { \# CPS } \\
\text { Observations }\end{array}$ & Merge Rate & $\begin{array}{c}\text { \# Merged CPS } \\
\text { Observations (With } \\
\text { Allocations) }\end{array}$ & $\begin{array}{c}\text { \# CPS } \\
\text { Observations } \\
\text { (With } \\
\text { Allocations) }\end{array}$ & $\begin{array}{l}\text { Merge Rate } \\
\text { (With } \\
\text { Allocations) }\end{array}$ \\
\hline 1973 & 10,116 & 20,863 & $48.5 \%$ & 14,223 & 25,875 & $55.0 \%$ \\
\hline 1974 & 14,618 & 19,612 & $74.5 \%$ & 21,062 & 24,831 & $84.8 \%$ \\
\hline 1975 & - & - & - & - & - & - \\
\hline 1976 & - & - & - & - & - & - \\
\hline 1977 & 26,063 & 36,299 & $71.8 \%$ & 38,604 & 46,319 & $83.3 \%$ \\
\hline 1978 & 23,661 & 33,707 & $70.2 \%$ & 37,658 & 45,826 & $82.2 \%$ \\
\hline 1979 & 21,800 & 38,320 & $56.9 \%$ & 38,573 & 54,167 & $71.2 \%$ \\
\hline 1980 & 23,421 & 38,970 & $60.1 \%$ & 42,596 & 55,272 & $77.1 \%$ \\
\hline 1981 & 21,404 & 36,635 & $58.4 \%$ & 37,229 & 48,778 & $76.3 \%$ \\
\hline 1982 & 23,379 & 37,547 & $62.3 \%$ & 37,651 & 48,806 & $77.1 \%$ \\
\hline 1983 & 23,303 & 36,942 & $63.1 \%$ & 36,973 & 48,549 & $76.2 \%$ \\
\hline 1984 & 21,313 & 36,232 & $58.8 \%$ & 35,152 & 48,752 & $72.1 \%$ \\
\hline 1985 & - & - & - & - & - & - \\
\hline 1986 & 19,129 & 35,778 & $53.5 \%$ & 29,577 & 46,636 & $63.4 \%$ \\
\hline 1987 & 21,114 & 41,573 & $50.8 \%$ & 30,277 & 46,806 & $64.7 \%$ \\
\hline 1988 & 22,436 & 38,616 & $58.1 \%$ & 27,921 & 43,165 & $64.7 \%$ \\
\hline 1989 & 22,810 & 41,776 & $54.6 \%$ & 28,409 & 47,106 & $60.3 \%$ \\
\hline 1990 & 24,330 & 42,342 & $57.5 \%$ & 30,483 & 47,717 & $63.9 \%$ \\
\hline 1991 & 24,131 & 41,784 & $57.8 \%$ & 30,222 & 47,091 & $64.2 \%$ \\
\hline 1992 & 23,792 & 40,847 & $58.2 \%$ & 29,787 & 45,979 & $64.8 \%$ \\
\hline 1993 & 22,580 & 41,316 & $54.7 \%$ & 29,426 & 48,277 & $61.0 \%$ \\
\hline 1994 & 19,883 & 37,931 & $52.4 \%$ & 26,450 & 44,121 & $59.9 \%$ \\
\hline 1995 & - & - & - & - & - & - \\
\hline 1996 & 18,462 & 32,466 & $56.9 \%$ & 25,963 & 39,113 & $66.4 \%$ \\
\hline 1997 & 18,140 & 31,812 & $57.0 \%$ & 26,375 & 39,375 & $67.0 \%$ \\
\hline 1998 & 16,976 & 30,761 & $55.2 \%$ & 26,260 & 39,677 & $66.2 \%$ \\
\hline 1999 & 16,223 & 34,942 & $46.4 \%$ & 26,580 & 44,814 & $59.3 \%$ \\
\hline 2000 & 15,449 & 49,155 & $31.4 \%$ & 26,093 & 66,095 & $39.5 \%$ \\
\hline
\end{tabular}




\begin{tabular}{|c|c|c|c|c|c|c|c|}
\hline 2001 & 18,538 & 49,586 & $37.4 \%$ & & 31,209 & 65,663 & $47.5 \%$ \\
\hline 2002 & 18,161 & 49,650 & $36.6 \%$ & & 30,582 & 65,176 & $46.9 \%$ \\
\hline 2003 & 19,085 & 49,243 & $38.8 \%$ & & 32,036 & 65,451 & $48.9 \%$ \\
\hline 2004 & 16,260 & 48,466 & $33.5 \%$ & & 27,414 & 64,428 & $42.5 \%$ \\
\hline 2005 & 17,470 & 48,572 & $36.0 \%$ & & 28,952 & 62,936 & $46.0 \%$ \\
\hline 2006 & 18,431 & 48,611 & $37.9 \%$ & & 29,349 & 62,433 & $47.0 \%$ \\
\hline 2007 & 18,873 & 48,640 & $38.8 \%$ & & 30,280 & 63,113 & $48.0 \%$ \\
\hline 2008 & 19,061 & 49,679 & $38.4 \%$ & & 29,948 & 62,927 & $47.6 \%$ \\
\hline $\begin{array}{l}\text { Average \# } \\
\text { of Matches }\end{array}$ & 20,013 & $\begin{array}{l}\text { Average \% } \\
\text { Matched }\end{array}$ & $52.1 \%$ & $\begin{array}{l}\text { Average \# } \\
\text { of Matches }\end{array}$ & 30,416 & $\begin{array}{l}\text { Average \% } \\
\text { Matched }\end{array}$ & $62.3 \%$ \\
\hline
\end{tabular}


Appendix Table 2. Summary Statistics by $2^{\text {nd }}$ Year Adjusted for Inflation (2008 Dollars)

\begin{tabular}{lrr}
\hline Variables & \multicolumn{1}{c}{ Mean } & Standard Deviation \\
\hline & & \\
Earnings and Income & & $34,597.12$ \\
& $27,481.12$ & 82.52 \\
Individual Earnings (\$) & 5.44 & $31,847.48$ \\
\% Change in Individual Earnings & $25,590.48$ & 84.63 \\
Individual Wage \& Salary Earnings (\$) & 5.12 & \\
\% Change in Individual Wage \& Salary Earnings & & 12.20 \\
& & 49.87 \\
Demographics & & 1.49 \\
& 37.58 & 39.93 \\
Age & 53.54 & 47.68 \\
\% Female & 3.29 & 48.71 \\
No. of Persons in Family & 20.52 & 34.44 \\
\% Less Than High School & 35.78 & 29.32 \\
\% High School & 43.69 & 19.78 \\
\% More Than High School & 86.15 & 48.16 \\
\% White & 9.51 & \\
\% Black & 4.34 & \\
\% Other & 62.86 & \\
\%arried & & \\
& & \\
\hline
\end{tabular}

